\title{
Reaction Pathways and Site Requirements for the Activation and Chemical Conversion of Methane on Ru-Based Catalysts
}

\author{
Junmei Wei and Enrique Iglesia* \\ Department of Chemical Engineering, University of California at Berkeley, Berkeley, California 94720
}

Received: June 24, 2003; In Final Form: September 29, 2003

\begin{abstract}
Kinetic and isotopic tracer and exchange measurements were used to determine the identity and reversibility of elementary steps required for $\mathrm{CH}_{4}$ reforming reactions on Ru-based catalyst. These studies provide a simple mechanistic picture and a unifying kinetic treatment for $\mathrm{CH}_{4} / \mathrm{CO}_{2}$ and $\mathrm{CH}_{4} / \mathrm{H}_{2} \mathrm{O}$ reforming reactions and $\mathrm{CH}_{4}$ decomposition. Forward kinetic rates were measured from net rates by correcting for the approach to equilibrium, after ruling out transport artifacts using pellet and bed dilution tests. The kinetic processes involved are exclusively limited by $\mathrm{C}-\mathrm{H}$ bond activation, and $\mathrm{CH}_{4}$ reaction rates are unaffected by the identity or the concentration of co-reactants $\left(\mathrm{H}_{2} \mathrm{O}, \mathrm{CO}_{2}\right)$. Similar normal kinetic isotopic effects $\left(k_{\mathrm{C}-\mathrm{H}} / k_{\mathrm{C}-\mathrm{D}}=1.40-1.51\right)$ were measured for $\mathrm{CO}_{2}$ reforming, $\mathrm{H}_{2} \mathrm{O}$ reforming, and $\mathrm{CH}_{4}$ decomposition, consistent with kinetically relevant $\mathrm{C}-\mathrm{H}$ bond activation steps. The ratio of $\mathrm{CH}_{4} / \mathrm{CD}_{4}$ cross-exchange to methane chemical conversion rates during the reaction of $\mathrm{CO}_{2}$ reforming with $\mathrm{CH}_{4}-\mathrm{CD}_{4}$ mixtures was 0.05 , suggesting that steps involving $\mathrm{C}-\mathrm{H}$ bond activation are essentially irreversible. Binomial $\mathrm{D}$-atom distributions in dihydrogen and water were obtained during reactions of $\mathrm{CH}_{4} / \mathrm{CO}_{2} / \mathrm{D}_{2}$ mixtures, and their D-contents were identical to those expected from complete equilibration between $\mathrm{D}_{2}$ and $\mathrm{H}$-atoms from reacted $\mathrm{CH}_{4}$, indicating that $\mathrm{H}-\mathrm{OH}$ and $\mathrm{H}-\mathrm{H}$ recombination steps are quasi-equilibrated. Reactions of ${ }^{12} \mathrm{CH}_{4} /{ }^{12} \mathrm{CO}_{2} /{ }^{13} \mathrm{CO}$ mixtures gave identical ${ }^{13} \mathrm{C}$ contents in $\mathrm{CO}$ and $\mathrm{CO}_{2}$, even far away from the $\mathrm{CO}_{2}$ reforming equilibrium; thus, $\mathrm{CO}_{2}$ activation is reversible and quasi-equilibrated during $\mathrm{CO}_{2}$ reforming on Ru-based catalysts, as expected from the kinetic irrelevance of co-reactant activation steps. These conclusions suggest that water-gas shift reactions are also equilibrated, as confirmed by chemical analyses of reaction products. Forward $\mathrm{CH}_{4}$ turnover rates increased with increasing $\mathrm{Ru}$ dispersion, but they were essentially unaffected by the identity of the support. This behavior reflects the higher reactivity of coordinatively unsaturated surface atoms, prevalent in small Ru clusters, for $\mathrm{C}-\mathrm{H}$ bond activation reactions, as previously inferred from the effect of crystal orientation on $\mathrm{CH}_{4}$ activation rates.
\end{abstract}

\section{Introduction}

$\mathrm{CH}_{4}$ reactions with $\mathrm{CO}_{2}$ or $\mathrm{H}_{2} \mathrm{O}$ can be used to produce synthesis gas mixtures for ultimate conversion to desired fuels and chemicals. Fischer and Tropsch ${ }^{1}$ first showed that group VIII metals ( $\mathrm{Ni}, \mathrm{Ru}, \mathrm{Rh}, \mathrm{Pt}, \mathrm{Pd}$, and $\mathrm{Ir}$ ) catalyzed $\mathrm{CO}_{2}-\mathrm{CH}_{4}$ reactions to form these $\mathrm{H}_{2}-\mathrm{CO}$ mixtures. Specifically, $\mathrm{Ru}$ clusters supported on $\mathrm{Al}_{2} \mathrm{O}_{3},{ }^{2-13} \mathrm{TiO}_{2},{ }^{2,14} \mathrm{MgO},{ }^{15,16} \mathrm{La}_{2} \mathrm{O}_{3},{ }^{7-9}$ $\mathrm{SiO}_{2},{ }^{12,17} \mathrm{NaY},{ }^{18}$ and carbon $^{2,19}$ effectively catalyze these reactions. The relevant elementary steps and the effects of metal dispersion and support on reaction rates have not been unequivocally established on supported $\mathrm{Ru}$ catalysts.

Bifunctional $\mathrm{CO}_{2}$ reforming pathways on $\mathrm{Ru} / \mathrm{Al}_{2} \mathrm{O}_{3}$ were proposed to involve $\mathrm{CH}_{4}$ decomposition on $\mathrm{Ru}$ and $\mathrm{CO}_{2}$ activation on $\mathrm{OH}$ groups in the $\mathrm{Al}_{2} \mathrm{O}_{3}$ support. ${ }^{11}$ Matsui et al. ${ }^{9}$ proposed a redox mechanism on $\mathrm{Ru}$ supported on $\mathrm{La}_{2} \mathrm{O}_{3}, \mathrm{ZrO}_{2}$, and $\mathrm{Y}_{2} \mathrm{O}_{3}$, in which $\mathrm{CH}_{4}$ forms $\mathrm{Ru}-\mathrm{CH}_{x}$ species and $\mathrm{CO}_{2}$ dissociates to form $\mathrm{CO}$ and chemisorbed oxygen atoms; $\mathrm{Ru}-$ $\mathrm{CH}_{x}$ then reacts with chemisorbed oxygen atoms to form $\mathrm{CO}$ and $\mathrm{Ru}$. Mark and Maier ${ }^{10}$ proposed rate-determining $\mathrm{CH}_{4}$ decomposition steps to form chemisorbed carbon and $\mathrm{H}_{2}$, and the reaction of carbon with $\mathrm{CO}_{2}$ in a fast process; this proposal led to a rate equation consistent with kinetic data:

* Author to whom correspondence should be addressed. Tel: (510) 642 9673. Fax: (510) 642-4778. E-mail: iglesia@cchem.berkeley.edu.

$$
r=\frac{k\left(P_{\mathrm{CH}_{4}}-\left(P_{\mathrm{H}_{2}}^{2} P_{\mathrm{CO}}{ }^{2} / \alpha P_{\mathrm{CO}_{2}}\right)\right)}{1+\left(P_{\mathrm{CO}}{ }^{2} / \beta P_{\mathrm{CO}_{2}}\right)}
$$

Studies of the stoichiometric activation of $\mathrm{CO}_{2}$ and $\mathrm{CH}_{4}$ on $\mathrm{Ru} /$ $\mathrm{Al}_{2} \mathrm{O}_{3}$ led to a proposal that $\mathrm{CH}_{4}$ dissociation is aided by chemisorbed oxygen formed via $\mathrm{CO}_{2}$ dissociation; the latter was in turn promoted by chemisorbed $\mathrm{H}$-atoms formed in $\mathrm{C}-\mathrm{H}$ bond activation. ${ }^{3} \mathrm{CO}_{2}$ reforming turnover rates on $\mathrm{Ru} / \mathrm{TiO}_{2}, \mathrm{Ru} / \mathrm{C}$, and $\mathrm{Ru} / \mathrm{Al}_{2} \mathrm{O}_{3}$ were influenced by conversion, because reverse steps contributed to measured rates as reactions approached equilibrium. ${ }^{2}$ After corrections for reverse reactions, forward rates were accurately described by a simple rate equation:

$$
r_{f}=k_{\mathrm{f}} P_{\mathrm{CH}_{4}}^{a} P_{\mathrm{CO}_{2}}^{b}
$$

where $a$ and $b$ are given by $0.52( \pm 0.36)$ and $0.21( \pm 0.40)$, respectively. This expression was shown to be consistent with a sequence involving slow and reversible $\mathrm{CH}_{4}$ dissociation to form $\mathrm{CH}_{x}$ species and irreversible slow decomposition of $\mathrm{CH}_{x} \mathrm{O}$ species to form $\mathrm{CO}$ and hydrogen, but these conclusions remained speculative because of large uncertainties in reported reaction orders.

Rostrup-Nielsen and Hansen ${ }^{16}$ reported the only parallel study of $\mathrm{CO}_{2}$ and $\mathrm{H}_{2} \mathrm{O}$ reforming reactions on $\mathrm{Ru}$ catalysts. They proposed that $\mathrm{CO}_{2}$ and $\mathrm{H}_{2} \mathrm{O}$ reforming mechanisms are similar 
on $\mathrm{Ru} / \mathrm{MgO}$, but found significantly higher reaction rates for $\mathrm{H}_{2} \mathrm{O}$ reforming $\left(80 \mathrm{kPa} \mathrm{H} \mathrm{H}_{2} \mathrm{O}, 20 \mathrm{kPa} \mathrm{CH}\right.$ ) $\left(8.9\right.$ mol site $\left.^{-1} \mathrm{~s}^{-1}\right)$ than for $\mathrm{CO}_{2}$ reforming ( $80 \mathrm{kPa} \mathrm{CO}_{2}, 20 \mathrm{kPa} \mathrm{CH}$ ) $(2.9 \mathrm{~mol}$ site $^{-1} \mathrm{~s}^{-1}$ ) at $823 \mathrm{~K}$. These authors proposed that the replacement of $\mathrm{H}_{2} \mathrm{O}$ co-reactants with $\mathrm{CO}_{2}$ introduced a kinetic bottleneck associated with $\mathrm{CO}_{2}$ activation, which became the ratedetermining step in $\mathrm{CO}_{2}$ reforming reactions

Several studies on model metal surfaces have concluded that $\mathrm{C}-\mathrm{H}$ bond activation is probably the kinetically relevant step in $\mathrm{CH}_{4}$ conversion reactions, but these studies have measured only rates of stoichiometric $\mathrm{CH}_{4}$ decomposition reactions, typically at temperatures much lower than those required to overcome kinetic and thermodynamic hurdles during $\mathrm{CH}_{4}$ reforming catalysis. ${ }^{20 \text { (and refs therein) }}$ For these systems and reactions, $\mathrm{C}-\mathrm{H}$ bond dissociation occurs more rapidly on step and kink sites than on terrace sites, apparently because of the higher reactivity of coordinatively unsaturated surface metal atoms. ${ }^{22-24}$ Stoichiometric activation of $\mathrm{CH}_{4}$ appears to depend sensitively on surface structure; this structure sensitivity, by the definition of Boudart, ${ }^{21}$ should lead to strong effects of metal cluster size on catalytic turnover rates. Yet, we have not found systematic studies of dispersion effects on $\mathrm{CH}_{4}$ reactions catalyzed by $\mathrm{Ru}$ or of the effects of Ru surface structure on catalytic reforming reactions.

The supports used to disperse Ru crystallites often influence $\mathrm{CO}_{2}$ reforming rates, but concurrent effects of supports on $\mathrm{Ru}$ dispersion, on transport artifacts, or on approach to equilibrium are seldom independently considered. Matsui ${ }^{9}$ found that $\mathrm{CH}_{4}$ conversions in $\mathrm{CO}_{2}$ reforming were higher on $\mathrm{Ru} / \mathrm{ZrO}_{2}$ and $\mathrm{Ru} /$ $\mathrm{La}_{2} \mathrm{O}_{3}$ than on $\mathrm{Ru} / \mathrm{Al}_{2} \mathrm{O}_{3}$, and proposed, without direct evidence, that such effects arose from the different reactivities of the various supports in $\mathrm{CO}_{2}$ activation. Ferreira-Aparicio et al. ${ }^{11}$ suggested that $\mathrm{OH}$ groups on supports catalyzed rate-determining $\mathrm{CO}_{2}$ activation steps. Bradford and Vannice ${ }^{2}$ found higher turnover rates when $\mathrm{Ru}$ was dispersed on $\mathrm{TiO}_{2}$ than on $\mathrm{Al}_{2} \mathrm{O}_{3}$ or carbon, even though $\mathrm{Ru}$ dispersions (from $\mathrm{H}_{2}$ chemisorption) were lower on $\mathrm{TiO}_{2}(51 \%)$ supports than on $\mathrm{Al}_{2} \mathrm{O}_{3}(78 \%)$ or carbon $(100 \%)$ supports. This study provided infrared evidence for the decoration of $\mathrm{Ru}$ crystallites with $\mathrm{TiO}_{x}$ species during catalyst reduction and proposed that such sites exhibit unique catalytic activity because of the resulting intimate metal-support contacts. The nature of these interactions, their specific role in kinetically relevant steps, and even the survival of these decoration effects in contact with $\mathrm{CO}_{2}$ and $\mathrm{H}_{2} \mathrm{O}$ at high temperatures remain unclear.

Here, we probe the identity and reversibility of elementary steps required for $\mathrm{H}_{2} \mathrm{O}$ and $\mathrm{CO}_{2}$ reforming of $\mathrm{CH}_{4}$ on supported $\mathrm{Ru}$ catalysts. We provide evidence for a catalytic sequence that rigorously combines the kinetics and pathways for water-gas shift, $\mathrm{CH}_{4}$ decomposition, and $\mathrm{CO}_{2}$ and $\mathrm{H}_{2} \mathrm{O}$ reforming reactions. Kinetic and isotopic experiments confirmed this sequence and established the sole kinetic relevance of $\mathrm{C}-\mathrm{H}$ bond activation and the essentially uncovered nature of $\mathrm{Ru}$ surfaces during steady-state catalysis. Reaction rates were measured in the absence of transport artifacts and rigorously corrected for the approach to equilibrium of reforming reactions. Similar rate constants determined for $\mathrm{C}-\mathrm{H}$ bond activation in $\mathrm{H}_{2} \mathrm{O}$ reforming, $\mathrm{CO}_{2}$ reforming, and $\mathrm{CH}_{4}$ decomposition reactions are compared on samples with varying $\mathrm{Ru}$ dispersion on $\mathrm{Al}_{2} \mathrm{O}_{3}$ and $\mathrm{ZrO}_{2}$ supports. Turnover rates were strongly influenced by $\mathrm{Ru}$ dispersion but essentially insensitive to the support used and to the identity or concentration of the co-reactant, consistent with $\mathrm{CH}_{4}$ activation rate-determining steps and with the kinetic irrelevance of $\mathrm{CO}_{2}$ and $\mathrm{H}_{2} \mathrm{O}$ activation. These conclusions resemble those reached in our recent studies of $\mathrm{CH}_{4}$ reforming and decomposition reactions on $\mathrm{Rh},{ }^{25} \mathrm{Pt},{ }^{26}$ $\mathrm{Ir},{ }^{27}$ and $\mathrm{Ni}^{28}$ catalysts, the evidence for which is presented elsewhere.

\section{Experimental Methods}

$\mathrm{Ru} / \mathrm{Al}_{2} \mathrm{O}_{3}$ with 1.6 and 3.2 wt $\% \mathrm{Ru}$ and $\mathrm{Ru} / \mathrm{ZrO}_{2}$ with 3.2 wt $\% \mathrm{Ru}$ were prepared by incipient wetness impregnation of $\mathrm{Al}_{2} \mathrm{O}_{3}$ or $\mathrm{ZrO}_{2}$ with an aqueous solution of $\mathrm{Ru}(\mathrm{NO})\left(\mathrm{NH}_{3}\right)_{3}$ (Alfa, CAS\#34513-98-9). Impregnated samples were dried at $393 \mathrm{~K}$ in ambient air and treated in flowing dry air (Airgas, UHP, 1.2 $\mathrm{cm}^{3} / \mathrm{g}$-s) by increasing the temperature to $873 \mathrm{~K}$ at $0.167 \mathrm{~K} \mathrm{~s}^{-1}$ and holding at $873 \mathrm{~K}$ for $5 \mathrm{~h}$. Samples were then treated in $\mathrm{H}_{2}$ (Airgas, UHP, $50 \mathrm{~cm}^{3} / \mathrm{g}$-s) by heating to $873 \mathrm{~K}$ at $0.167 \mathrm{~K} \mathrm{~s}^{-1}$ and holding at $873 \mathrm{~K}$ for $2 \mathrm{~h}$. The $3.2 \mathrm{wt} \% \mathrm{Ru} / \mathrm{Al}_{2} \mathrm{O}_{3}$ sample was also treated in $\mathrm{H}_{2}$ (Airgas, UHP, $50 \mathrm{~cm}^{3} / \mathrm{g}$-s) by increasing the temperature to $1023 \mathrm{~K}$ at $0.167 \mathrm{~K} \mathrm{~s}^{-1}$ and holding at 1023 $\mathrm{K}$ for $2 \mathrm{~h}$ in order to vary the size of $\mathrm{Ru}$ clusters. $\mathrm{Al}_{2} \mathrm{O}_{3}(160$ $\mathrm{m}^{2} / \mathrm{g}$ ) was prepared by treating $\mathrm{Al}(\mathrm{OH})_{3}$ (Aldrich, 21645-51-2) in flowing dry air (Airgas, UHP, $1.2 \mathrm{~cm}^{3} / \mathrm{g}$-s) while increasing the temperature to $923 \mathrm{~K}$ at $0.167 \mathrm{~K} \mathrm{~s}^{-1}$ and holding at $923 \mathrm{~K}$ for $5 \mathrm{~h}$, a procedure that leads to $\gamma-\mathrm{Al}_{2} \mathrm{O}_{3} \cdot{ }^{29} \mathrm{ZrO}_{2}\left(45 \mathrm{~m}^{2} / \mathrm{g}\right)$ was prepared by hydrolysis of a $0.5 \mathrm{M}$ aqueous solution of $\mathrm{ZrOCl}_{2} \cdot 8 \mathrm{H}_{2} \mathrm{O}$ (Aldrich, $>98 \mathrm{wt} \%$ ) at a constant $\mathrm{pH}$ of 10 , maintained by addition of controlled amounts of a $14.8 \mathrm{M} \mathrm{NH}_{4}$ $\mathrm{OH}$ solution. ${ }^{30}$ The precipitates were immediately filtered and washed repeatedly by redispersing it in a warm $\mathrm{NH}_{4} \mathrm{OH}$ solution $(\mathrm{pH} 10, \sim 333 \mathrm{~K})$ to remove residual $\mathrm{Cl}$ ions, until no $\mathrm{Cl}$ ions were detected by a $\mathrm{AgNO}_{3}$ test $\left(\mathrm{Cl}^{-}<10 \mathrm{ppm}\right)$. The samples were then dried at $393 \mathrm{~K}$ overnight in ambient air and treated in flowing dry air (Airgas, UHP, $1.2 \mathrm{~cm}^{3} / \mathrm{g}$-s) by heating to $923 \mathrm{~K}$ at $0.167 \mathrm{~K} \mathrm{~s}^{-1}$ and holding at $923 \mathrm{~K}$ for $5 \mathrm{~h}$. X-ray diffraction showed the predominant presence of monoclinic $\mathrm{ZrO}_{2}$.

$\mathrm{Ru}$ dispersion was measured by volumetric $\mathrm{H}_{2}$ chemisorption at $373 \mathrm{~K}^{31}$ using a Quantasorb chemisorption analyzer (Quantachrome Corp.). Catalysts were reduced in $\mathrm{H}_{2}$ at $873 \mathrm{~K}$ for 2 $\mathrm{h}$, and then evacuated at $873 \mathrm{~K}$ for $0.5 \mathrm{~h}$. After cooling to 373 $\mathrm{K}$, a $\mathrm{H}_{2}$ chemisorption isotherm was measured between 3 and $50 \mathrm{kPa}$. A backsorption isotherm was measured by repeating this procedure after evacuating samples at $373 \mathrm{~K}$ for $0.5 \mathrm{~h}$. Both isotherms were extrapolated to zero $\mathrm{H}_{2}$ pressure and their difference used as a measure of the uptake of strongly chemisorbed hydrogen. $\mathrm{Ru}$ dispersions were calculated by assuming that one hydrogen atom chemisorbed on each surface $\mathrm{Ru} ;{ }^{31}$ dispersion values are shown in Table 1 for each of the catalysts used in this study.

Catalytic rates were measured by placing samples $(5 \mathrm{mg}$, $250-425 \mu \mathrm{m})$ within a quartz or steel tube $(8 \mathrm{~mm}$ inner diameter) with a type $\mathrm{K}$ thermocouple enclosed within a sheath in contact with the catalyst bed. Samples were diluted with ground, acid-washed quartz powder (500 mg, 250-425 $\mu \mathrm{m})$ to avoid temperature gradients. Transport artifacts were ruled out using pellet and bed dilution with the pure support without detectable changes in rates or selectivities, as shown in the Appendix. The effects of $\mathrm{CH}_{4}, \mathrm{H}_{2} \mathrm{O}$, and $\mathrm{CO}_{2}$ pressures on $\mathrm{CH}_{4}$ reaction rates were measured at $823-1023 \mathrm{~K}$ and $0.1-0.5 \mathrm{MPa}$ total pressure over a wide range of reactant concentrations. Reactant mixtures were prepared using $50 \%$ $\mathrm{CH}_{4} / \mathrm{Ar}$ (Matheson) and 50\% $\mathrm{CO}_{2} / \mathrm{Ar}$ (Matheson) certified mixtures and $\mathrm{He}$ (Airgas, UHP) as balance. For $\mathrm{H}_{2} \mathrm{O}$ reforming reactions, $\mathrm{H}_{2} \mathrm{O}$ was introduced using a syringe pump (ColeParmer, 74900 series). All transfer lines after $\mathrm{H}_{2} \mathrm{O}$ introduction 
TABLE 1: Forward $\mathrm{CH}_{4}$ Turnover Rate on Supported Ru Catalysts (873 K, 20 kPa $\mathrm{CH}_{4}, 20 \mathrm{kPa} \mathrm{CO}_{2}$ or $\left.\mathrm{H}_{2} \mathrm{O}\right)$

\begin{tabular}{|c|c|c|c|c|c|c|}
\hline \multirow[b]{2}{*}{ catalyst } & \multirow[b]{2}{*}{$\begin{array}{c}\text { reduction } \\
\text { temperature }(\mathrm{K})\end{array}$} & \multirow[b]{2}{*}{$\begin{array}{c}\mathrm{Ru} \\
\text { dispersion (\%) }\end{array}$} & \multicolumn{3}{|c|}{ Forward $\mathrm{CH}_{4}$ Turnover Rate $\left(\mathrm{s}^{-1}\right)$} & \multirow[b]{2}{*}{ reference } \\
\hline & & & $\mathrm{CH}_{4}-\mathrm{CO}_{2}$ & $\mathrm{CH}_{4}-\mathrm{H}_{2} \mathrm{O}$ & $\begin{array}{c}\mathrm{CH}_{4} \\
\text { decomposition }\end{array}$ & \\
\hline 1.6 wt $\% \mathrm{Ru} / \gamma-\mathrm{Al}_{2} \mathrm{O}_{3}$ & 873 & 55.5 & 4.8 & 4.9 & & this study \\
\hline $3.2 \mathrm{wt} \% \mathrm{Ru} / \gamma-\mathrm{Al}_{2} \mathrm{O}_{3}$ & 873 & 44.2 & 3.1 & 3.3 & 3.1 & this study \\
\hline $3.2 \mathrm{wt} \% \mathrm{Ru} / \gamma-\mathrm{Al}_{2} \mathrm{O}_{3}$ & 1023 & 33.1 & 2.7 & 2.6 & & this study \\
\hline $3.2 \mathrm{wt} \% \mathrm{Ru} / \mathrm{ZrO}_{2}$ & 873 & 29.8 & 2.5 & 2.3 & 2.2 & this study \\
\hline $1.6 \mathrm{wt} \% \mathrm{Ru} / \eta-\mathrm{Al}_{2} \mathrm{O}_{3}$ & & 78.0 & $15.3^{a}$ & & & 2 \\
\hline $4.8 \mathrm{wt} \% \mathrm{Ru} / \mathrm{C}$ & & 100 & $1.1^{a}$ & & & 2 \\
\hline $1.0 \mathrm{wt} \% \mathrm{Ru} / \gamma-\mathrm{Al}_{2} \mathrm{O}_{3}$ & & 5.5 & $1.2^{a}$ & & & 3 \\
\hline 0.64 wt $\% \mathrm{Ru} / \gamma-\mathrm{Al}_{2} \mathrm{O}_{3}$ & & 51.0 & $5.1^{a}$ & & & 12 \\
\hline 1.0 wt $\% \mathrm{Ru} / \mathrm{NaY}$ & & 28.0 & $2.6^{a}$ & & & 18 \\
\hline
\end{tabular}

${ }^{a}$ Net rates were corrected to forward rates by approach to equilibrium using eq 5 , then extrapolated to our reaction conditions $(873 \mathrm{~K}, 20 \mathrm{kPa}$ $\left.\mathrm{CH}_{4}\right)$ using $r=A \exp (-\mathrm{Ea} / \mathrm{RT}) P_{\mathrm{CH}_{4}}$.
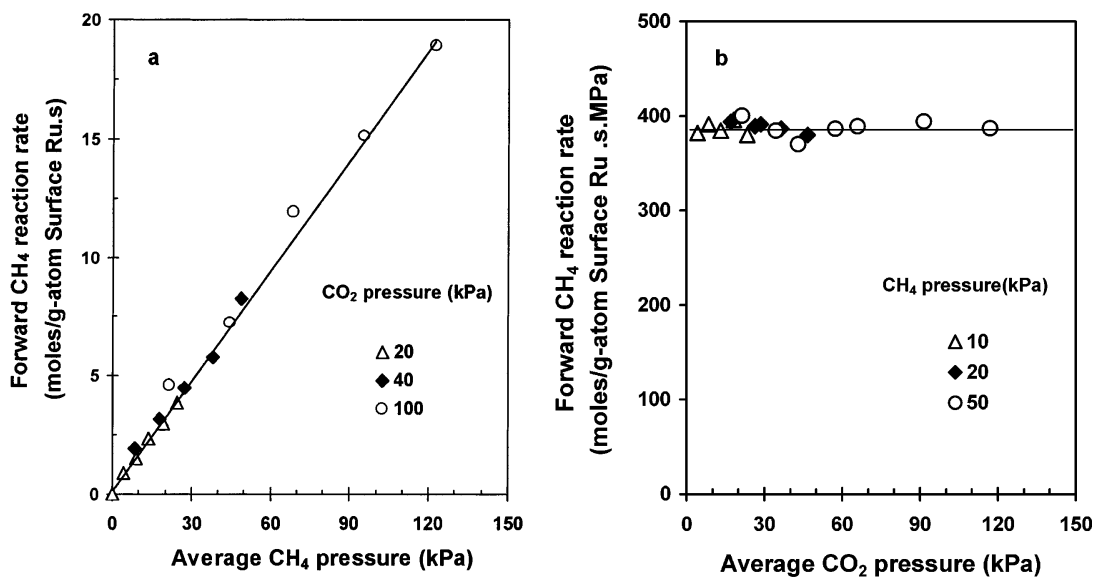

Figure 1. Effects of $\mathrm{CH}_{4}$ (a) and $\mathrm{CO}_{2}$ (b) partial pressure on forward $\mathrm{CH}_{4}$ reaction rate for $\mathrm{CO}_{2}$ reforming of $\mathrm{CH}_{4}$ on $3.2 \mathrm{wt} \% \mathrm{Ru} / \mathrm{Al}_{2} \mathrm{O}_{3}$ reduced at $873 \mathrm{~K}\left(5 \mathrm{mg}\right.$ catalyst, $873 \mathrm{~K}$, total flow rate $100 \mathrm{~cm}^{3} / \mathrm{min}$, balance $\mathrm{He}$, average pressure is the average of inlet and outlet pressures of the reactor).

were kept above $373 \mathrm{~K}$ to avoid condensation. Reactant and product concentrations were measured with a Hewlett-Packard 6890 gas chromatograph using a Carboxen 1000 packed column $(3.2 \mathrm{~mm} \times 2 \mathrm{~m})$ and thermal conductivity detection. Unless otherwise noted, catalysts were reduced at $873 \mathrm{~K}$ before $\mathrm{CH}_{4}$ reforming reactions. No products were detected at $823-1023$ $\mathrm{K}$ in empty reactors.

$\mathrm{Ru} / \mathrm{Al}_{2} \mathrm{O}_{3}$ and $\mathrm{Ru} / \mathrm{ZrO}_{2}$ catalysts $\left(20 \mathrm{mg}\right.$, treated in $\mathrm{H}_{2}$ at 873 $\mathrm{K} ; 3.2 \mathrm{wt} \%$ ) diluted with $500 \mathrm{mg}$ quartz powder were used for $\mathrm{CH}_{4}$ and $\mathrm{CD}_{4}$ decomposition reactions at $873 \mathrm{~K}$. Chemical compositions were measured by on-line mass spectrometry (Leybold Inficon, Transpector Series). Reactant mixtures with $20 \% \mathrm{CH}_{4} / \mathrm{Ar}$ or $20 \% \mathrm{CD}_{4} / \mathrm{Ar}$ were prepared using $50 \% \mathrm{CH}_{4} /$ $\mathrm{Ar}$ (Matheson, certified mixture) or $\mathrm{CD}_{4}$ (Isotec, chemical purity $>99.0 \%$ ) with Ar (Airgas, UHP) as an inert internal standard used for accurate $\mathrm{CH}_{4}$ conversion measurements. Initial $\mathrm{CH}_{4}$ decomposition rates were used to estimate rate constants for $\mathrm{CH}_{4}$ decomposition using the observed linear dependence of rates on $\mathrm{CH}_{4}$ concentration.

Isotopic tracer studies were carried out on $3.2 \mathrm{wt} \% \mathrm{Ru} / \mathrm{Al}_{2} \mathrm{O}_{3}$ reduced at $873 \mathrm{~K}$ with a $44.2 \% \mathrm{Ru}$ dispersion using a transient flow apparatus with short hydrodynamic delays $(<5 \mathrm{~s})$. Chemical and isotopic compositions were measured using on-line mass spectrometry (Leybold Inficon, Transpector Series). CD 4 (Isotec, chemical purity $>99.0 \%$ ), $\mathrm{D}_{2} \mathrm{O}$ (Isotec, chemical purity $>$ $99.0 \%$ ), and $5 \% \mathrm{D}_{2} / \mathrm{Ar}$ and ${ }^{13} \mathrm{CO}$ (Isotec, chemical purity $>$ $99.0 \%$ ) were used as reactants without further purification. Intensities at 15 and 17-20 amu were used to measure methane isotopomer concentrations. $\mathrm{CH}_{4}$ and $\mathrm{CD}_{4}$ standard fragmentation patterns were measured, and those for $\mathrm{CHD}_{3}, \mathrm{CH}_{2} \mathrm{D}_{2}$, and $\mathrm{CH}_{3} \mathrm{D}$ were calculated using reported methods. ${ }^{32}$ Intensities at 18, 19, and 20 amu were used to determine water isotopomers and those at $28,29,44$, and 45 amu to measure ${ }^{12} \mathrm{CO},{ }^{13} \mathrm{CO},{ }^{12} \mathrm{CO}_{2}$, and ${ }^{13} \mathrm{CO}_{2}$ concentrations, respectively. Detailed experimental conditions are shown together with the corresponding data in the Results section.

Carbon formation rates were measured during reforming reactions at $873 \mathrm{~K}$ using a tapered element quartz oscillating microbalance (Rupprecht \& Patashnick, Series 1500). Catalyst treatment procedures and reaction conditions were similar to those used in kinetic measurements.

\section{Results and Discussion}

Kinetic Dependence of Reforming Rates on $\mathrm{CH}_{4}, \mathrm{CO}_{2}$, and $\mathrm{H}_{2} \mathrm{O}$ Partial Pressures. The kinetic dependence of $\mathrm{CH}_{4}$ reforming rates on $\mathrm{CH}_{4}, \mathrm{CO}_{2}$, and $\mathrm{H}_{2} \mathrm{O}$ concentrations was measured on 3.2 wt $\% \mathrm{Ru} / \mathrm{Al}_{2} \mathrm{O}_{3}$ treated at $873 \mathrm{~K}$ in $\mathrm{H}_{2}(44.2 \% \mathrm{Ru}$ dispersion) at conditions leading to stable rates and undetectable carbon formation. Filament carbon formation was not detected in parallel microbalance experiments or by transmission electron microscopy analyses of catalyst samples after use.

Figure 1 shows the effects of $\mathrm{CH}_{4}$ and $\mathrm{CO}_{2}$ pressures on forward $\mathrm{CH}_{4}$ turnover rate $\left(r_{\mathrm{f}}\right.$, normalized by the number of exposed surface $\mathrm{Ru}$ atoms) at $873 \mathrm{~K}$ and $100-500 \mathrm{kPa}$ total pressure. Net rate measurements far from equilibrium require very low $\mathrm{CH}_{4}$ conversions at low temperatures, because of unfavorable thermodynamics, and they become impractical at high temperatures, because very fast reaction rates lead to ubiquitous temperature and concentration gradients. Measured reaction rates were corrected for approach to equilibrium $(\eta)$ using thermodynamic data ${ }^{33}$ and prevalent pressures of reactants 


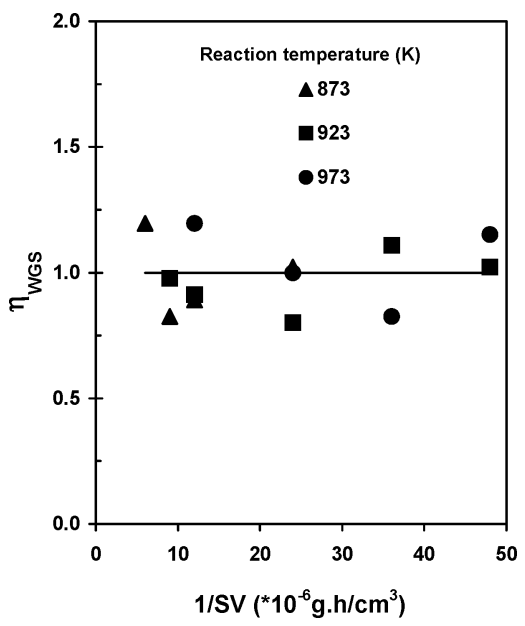

Figure 2. Extent of water-gas-shift equilibrium at different reaction temperatures as a function of space velocity on $3.2 \mathrm{wt} \% \mathrm{Ru} / \mathrm{Al}_{2} \mathrm{O}_{3}$ catalysts reduced at $873 \mathrm{~K}(44.2 \% \mathrm{Ru}$ dispersion). (Reaction conditions: $\mathrm{CO}_{2} / \mathrm{CH}_{4} / \mathrm{Ar}=1: 1: 2,100 \mathrm{kPa}$ total pressure, $\eta_{\mathrm{WGS}}=\left(\left[P_{\mathrm{CO}}\right]-\right.$ $\left.\left.\left[P_{\mathrm{H}_{2} \mathrm{O}}\right]\right) /\left(\left[P_{\mathrm{H}_{2}}\right]\left[P_{\mathrm{CO}_{2}}\right] K_{\mathrm{WGS}}\right)\right)$.

and products to give forward rates for $\mathrm{CH}_{4}-\mathrm{CO}_{2}$ and $\mathrm{CH}_{4}-$ $\mathrm{H}_{2} \mathrm{O}$ reactions:

$$
\begin{aligned}
& \eta_{1}=\frac{\left[P_{\mathrm{CO}}\right]^{2}\left[P_{\mathrm{H}_{2}}\right]^{2}}{\left[P_{\mathrm{CH}_{4}}\right]\left[P_{\mathrm{CO}_{2}}\right]} \times \frac{1}{K_{\mathrm{EQ} 1}} \\
& \eta_{2}=\frac{\left[P_{\mathrm{CO}}\right]\left[P_{\mathrm{H}_{2}}\right]^{3}}{\left[P_{\mathrm{CH}_{4}}\right]\left[P_{\mathrm{H}_{2} \mathrm{O}}\right]} \times \frac{1}{K_{\mathrm{EQ} 2}}
\end{aligned}
$$

In these equations, $\left[P_{j}\right]$ is the average partial pressure of species $j$ (in units of atm) in the reactor. Average pressures were used in order to correct for minor depletion of reactants along the catalyst bed. $K_{\mathrm{EQ} 1}$ and $K_{\mathrm{EQ} 2}$ are equilibrium constants for each reforming reaction. ${ }^{33}$ The $(1-\eta)$ values were larger than 0.8 for all catalytic measurements reported here. Net reaction rates $\left(r_{\mathrm{n}}\right)$ are used to obtain forward reaction rates using

$$
r_{\mathrm{n}}=\left(r_{\mathrm{f}}-r_{\mathrm{r}}\right)=r_{\mathrm{f}}(1-\eta)
$$

where $r_{\mathrm{r}}$ is the reverse reaction rate. ${ }^{34}$ This equation accurately described the observed effects of reactor residence time and $\mathrm{CH}_{4}$ conversion level on reforming rates.

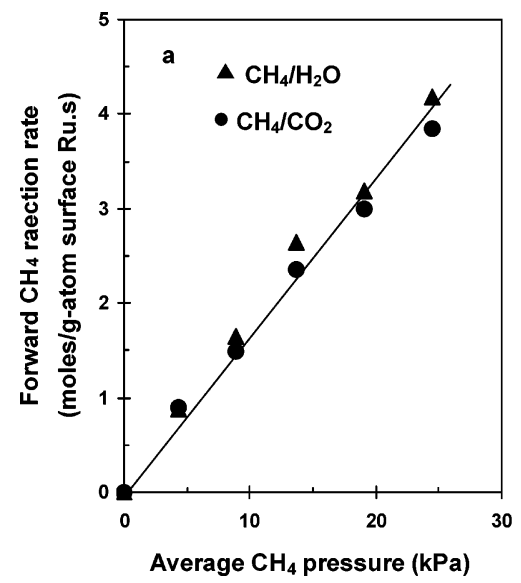

Forward $\mathrm{CH}_{4}-\mathrm{CO}_{2}$ reaction rates increased linearly with increasing $\mathrm{CH}_{4}$ partial pressure $(5-125 \mathrm{kPa})$ at $873 \mathrm{~K}$ and were independent of $\mathrm{CO}_{2}$ partial pressure (5-125 $\mathrm{kPa}$ ) (Figure 1(a,b)). Forward rates were also insensitive to $\mathrm{CO}, \mathrm{H}_{2}$, and $\mathrm{H}_{2} \mathrm{O}$ pressures, whether these pressures were varied by adding these species to the inlet stream or by changing residence times and $\mathrm{CH}_{4}$ conversions. Measured concentrations during $\mathrm{CH}_{4}$ reforming corresponded to equilibrated water-gas-shift (WGS) reactions at all temperatures between 823 and $1023 \mathrm{~K}$ (Figure 2). $\mathrm{CH}_{4}-$ $\mathrm{CO}_{2}$ reaction rates are simply described by a first-order dependence in $\mathrm{CH}_{4}$ and a zero-order dependence in $\mathrm{CO}_{2}$,

$$
r_{\mathrm{f}}=k_{\mathrm{CO}_{2}} P_{\mathrm{CH}_{4}}
$$

Once reverse reaction rates are considered using eqs $3-5$, this expression describes $\mathrm{CO}_{2}$ reforming rates at all temperatures $(823-1023 \mathrm{~K})$.

More complex rate expressions reported in previous studies ${ }^{3,10}$ may reflect transport artifacts or nonrigorous accounts of reverse reactions. Equation 6 is consistent with $\mathrm{CH}_{4}$ activation on $\mathrm{Ru}$ surfaces as the sole kinetically relevant elementary step and with fast steps involving recombinative hydrogen desorption to form $\mathrm{H}_{2}$ and reactions of $\mathrm{CO}_{2}$ with $\mathrm{CH}_{4}$-derived chemisorbed species to form $\mathrm{CO}$. These fast steps maintain Ru surfaces essentially uncovered by reactive intermediates during $\mathrm{CH}_{4}-\mathrm{CO}_{2}$ reactions. Otherwise, higher $\mathrm{CO}_{2}$ pressure would increase the rate of removal of adsorbed intermediates and lead to positive effects on $\mathrm{CH}_{4}$ reforming rates. These data do not preclude the presence of completely unreactive residues during catalysis, an issue that we address below.

The kinetic irrelevance of carbon removal by co-reactants and the mechanistic equivalence of $\mathrm{H}_{2} \mathrm{O}$ and $\mathrm{CO}_{2}$ reforming reactions were confirmed by $\mathrm{CH}_{4}-\mathrm{H}_{2} \mathrm{O}$ reaction rates measured on $3.2 \mathrm{wt} \% \mathrm{Ru} / \mathrm{Al}_{2} \mathrm{O}_{3}$. These rates are shown together with those for $\mathrm{CH}_{4}-\mathrm{CO}_{2}$ reactions in Figure 3 as a function of $\mathrm{CH}_{4}$ and co-reactant pressures. Forward $\mathrm{CH}_{4}-\mathrm{H}_{2} \mathrm{O}$ reaction rates are proportional to $\mathrm{CH}_{4}$ partial pressures $(5-25 \mathrm{kPa})$ and independent of $\mathrm{H}_{2} \mathrm{O}$ partial pressure $(5-25 \mathrm{kPa})$. As in $\mathrm{CH}_{4}-\mathrm{CO}_{2}$ reactions, rates are simply described by

$$
r_{\mathrm{f}}=k_{\mathrm{H}_{2} \mathrm{O}} P_{\mathrm{CH}_{4}}
$$

Rate constants for $\mathrm{H}_{2} \mathrm{O}\left(k_{\mathrm{H}_{2} \mathrm{O}}\right)$ and $\mathrm{CO}_{2}\left(k_{\mathrm{CO}_{2}}\right)$ reforming are similar to each other at each reaction temperature (Figure 4) and show similar activation energies. The corresponding preexponential factors for these rate constants are shown in Table

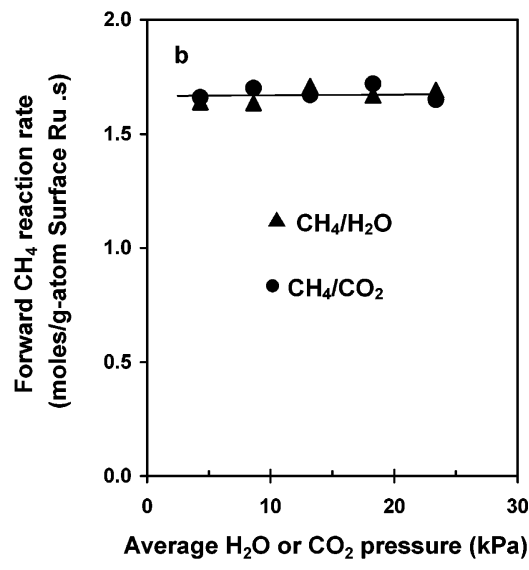

Figure 3. Effects of $\mathrm{CH}_{4}$ (a) and $\mathrm{CO}_{2}$ or $\mathrm{H}_{2} \mathrm{O}$ (b) partial pressure on forward $\mathrm{CH}_{4}$ reaction rate for $\mathrm{CH}_{4}-\mathrm{CO}_{2}$ and $\mathrm{CH}_{4}-\mathrm{H}_{2} \mathrm{O}$ reactions on 3.2 wt $\% \mathrm{Ru} / \mathrm{Al}_{2} \mathrm{O}_{3}$ reduced at $873 \mathrm{~K}\left(44.2 \% \mathrm{Ru}\right.$ dispersion) $\left(5 \mathrm{mg}\right.$ of catalyst, $873 \mathrm{~K}$, total flow rate $100 \mathrm{~cm}^{3} / \mathrm{min} 20 \mathrm{kPa} \mathrm{CO}_{2}$ or $\mathrm{H}_{2} \mathrm{O}$ in $($ a) and $10 \mathrm{kPa}$ $\mathrm{CH}_{4}$ in (b), balance $\mathrm{He}$ ). 
TABLE 2: Forward $\mathrm{CH}_{4}$ Reaction Rate, Rate Constants, and Kinetic Isotope Effects for $\mathrm{CH}_{4}$ Reforming Reactions on 3.2 wt \% $\mathrm{Ru} / \mathrm{Al}_{2} \mathrm{O}_{3}$ Reduced at $873 \mathrm{~K}\left(44.2 \%\right.$ metal dispersion) $\left(873 \mathrm{~K}, 25 \mathrm{kPa} \mathrm{CH} 4\right.$ or $\mathrm{CD}_{4}, 25 \mathrm{KPa} \mathrm{CO}_{2}$ or $\mathrm{H}_{2} \mathrm{O}$, balance Ar, total flow rate $100 \mathrm{~cm}^{3} / \mathrm{min}$ )

\begin{tabular}{|c|c|c|c|c|c|c|}
\hline \multirow[b]{2}{*}{ co-reactant } & \multirow{2}{*}{$\begin{array}{l}\text { turnover } \\
\text { rate }\left(\mathrm{s}^{-1}\right)^{a}\end{array}$} & \multirow{2}{*}{$\begin{array}{l}\text { rate constant } \\
\left(\mathrm{s}^{-1} \mathrm{kPa}^{-1}\right)\end{array}$} & \multirow{2}{*}{$\begin{array}{l}\text { kinetic isotope } \\
\text { effect }^{b}\end{array}$} & \multirow{2}{*}{$\begin{array}{l}\text { activation energy } \\
(\mathrm{kJ} / \mathrm{mol})\end{array}$} & \multicolumn{2}{|c|}{$\begin{array}{l}\text { Pre-Exponential Factor } \\
\qquad\left(\mathrm{s}^{-1} \mathrm{kPa}^{-1}\right)\end{array}$} \\
\hline & & & & & measured & estimated $^{c}$ \\
\hline $\mathrm{CO}_{2}$ & 3.9 & 0.16 & 1.42 & 96 & $8.7 \times 10^{4}$ & $5.5 \times 10^{3}$ \\
\hline $\mathrm{H}_{2} \mathrm{O}$ & 4.2 & 0.18 & 1.40 & 91 & $4.7 \times 10^{4}$ & $5.5 \times 10^{3}$ \\
\hline none & 3.8 & 0.15 & 1.51 & 99 & $8.4 \times 10^{4}$ & $5.5 \times 10^{3}$ \\
\hline
\end{tabular}

${ }^{a}$ Initial $\mathrm{CH}_{4}$ turnover rate on Ru surface. ${ }^{b} k_{\mathrm{CH}_{4}} / k_{\mathrm{CD}_{4}} \cdot{ }^{c}$ Calculated on the basis of transition-state theory treatments of $\mathrm{CH}_{4}$ activation steps proceeding via an immobile activated complex. ${ }^{32}$

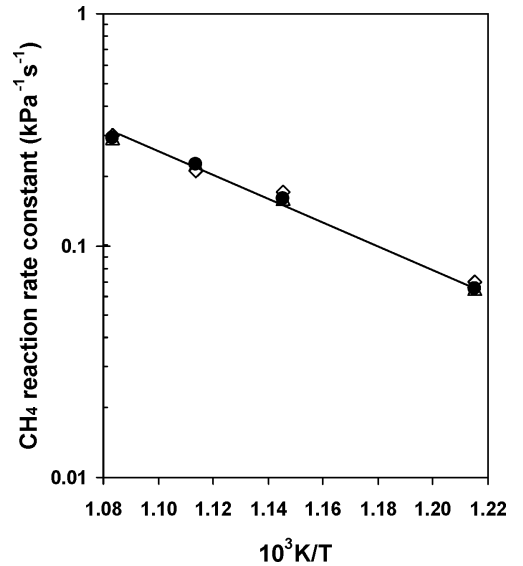

Figure 4. Arrhenius plots for $\mathrm{CO}_{2}$ reforming $(\bullet), \mathrm{H}_{2} \mathrm{O}$ reforming $(\diamond)$, and $\mathrm{CH}_{4}$ decomposition $(\triangle)$ rate constants on $3.2 \mathrm{wt} \% \mathrm{Ru} / \mathrm{Al}_{2} \mathrm{O}_{3}$ reduced at $873 \mathrm{~K}(44.2 \% \mathrm{Ru}$ dispersion).

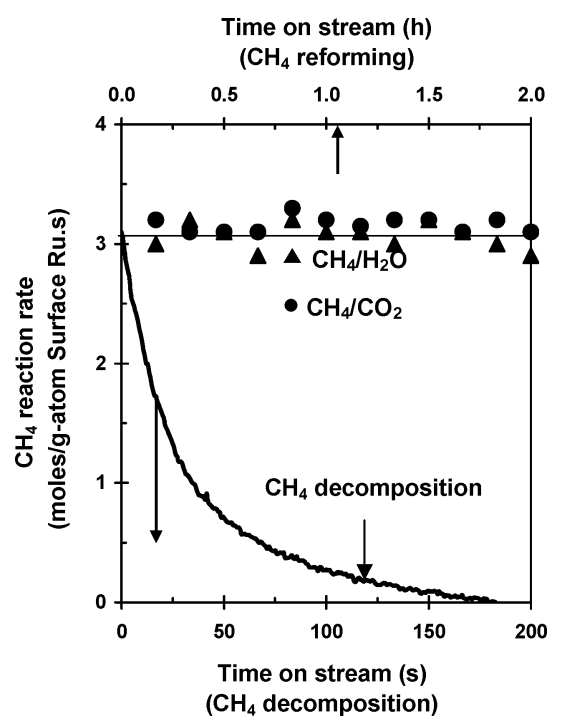

Figure 5. $\mathrm{CH}_{4}$ reaction rate for $\mathrm{CH}_{4}$ decomposition and reforming reactions on $3.2 \mathrm{wt} \% \mathrm{Ru} / \mathrm{Al}_{2} \mathrm{O}_{3}$ catalyst reduced at $873 \mathrm{~K}(44.2 \% \mathrm{Ru}$ dispersion) $\left(873 \mathrm{~K}, 20 \mathrm{kPa} \mathrm{CH}_{4}, 100 \mathrm{kPa}\right.$ total pressure, total flow rate $100 \mathrm{~cm}^{3} / \mathrm{min}$ ).

2. Preexponential factors predicted from transition-state theory treatments of $\mathrm{CH}_{4}$ activation steps proceeding via immobile activated complexes ${ }^{35}$ are also shown in Table 1 . The measured values are larger than theoretical estimates, but become similar if limited mobility is assumed for activated complexes.

$\mathrm{CH}_{4}-\mathrm{CO}_{2}$ and $\mathrm{CH}_{4}-\mathrm{H}_{2} \mathrm{O}$ reaction rate constants are also similar to those measured during the early stages of $\mathrm{CH}_{4}$ decomposition in the absence of either $\mathrm{H}_{2} \mathrm{O}$ or $\mathrm{CO}_{2}$ co-reactants on 3.2 wt $\% \mathrm{Ru} / \mathrm{Al}_{2} \mathrm{O}_{3}$ (Figure 5, Table 2). It appears that the sole kinetically relevant step in catalytic $\mathrm{CH}_{4}$ reactions with $\mathrm{H}_{2} \mathrm{O}$ or $\mathrm{CO}_{2}$ to form $\mathrm{H}_{2}-\mathrm{CO}$ mixtures and in stoichiometric $\mathrm{CH}_{4}$ decomposition to form $\mathrm{C}^{*}$ and $\mathrm{H}_{2}$ on $\mathrm{Ru}$ is the initial activation of a $\mathrm{C}-\mathrm{H}$ bond catalyzed by interactions with $\mathrm{Ru}$ surface atoms.

Figure 4 shows Arrhenius plots for $\mathrm{CH}_{4}$ reforming and decomposition rate constants. Activation energies for $\mathrm{CO}_{2}(96$ $\mathrm{kJ} / \mathrm{mol}), \mathrm{H}_{2} \mathrm{O}$ reforming $(91 \mathrm{~kJ} / \mathrm{mol})$ and $\mathrm{CH}_{4}$ decomposition (99 $\mathrm{kJ} / \mathrm{mol}$ ) are similar (Table 2), consistent with similar kinetically relevant steps. These activation energies resemble those reported previously for $\mathrm{CO}_{2}$ reforming on $1.0 \mathrm{wt} \% \mathrm{Ru} /$ $\mathrm{Al}_{2} \mathrm{O}_{3}(92.4 \mathrm{~kJ} / \mathrm{mol})^{2}$ and $1.6 \mathrm{wt} \% \mathrm{Ru} / \mathrm{Al}_{2} \mathrm{O}_{3}$ and $4.8 \mathrm{wt} \%$ $\mathrm{Ru} / \mathrm{C}(106 \mathrm{~kJ} / \mathrm{mol})^{3}$, but they are much larger than reported for $\mathrm{CH}_{4}$ activation on $\mathrm{Ru}$ single crystals ${ }^{36,37}$ and on $\mathrm{Ru} / \mathrm{SiO}_{2}{ }^{38}$ at lower temperatures. An activation energy of $51 \pm 6 \mathrm{~kJ} / \mathrm{mol}$ was reported for $\mathrm{CH}_{4}$ activation on $\mathrm{Ru}(0001)$ from the amount of carbon deposited after various elapsed times. ${ }^{36}$ Even lower values $(36.1 \mathrm{~kJ} / \mathrm{mol})$ were measured by others on similar $\mathrm{Ru}$ (0001) surfaces from electron energy loss measurements of chemisorbed carbon ${ }^{37}$ and on $\mathrm{Ru} / \mathrm{SiO}_{2}(29 \mathrm{~kJ} / \mathrm{mol})$ using a pulse microreactor. ${ }^{38}$

Density functional theory (DFT) led to $85 \mathrm{~kJ} / \mathrm{mol}^{39}$ and 78 $\mathrm{kJ} / \mathrm{mol}^{40}$ estimates of activation energies for $\mathrm{CH}_{4}$ activation on $\mathrm{Ru}$ (0001) surfaces. These estimates lie between values measured in the present study for catalytic and stoichiometric $\mathrm{CH}_{4}$ reaction $(91-107 \mathrm{~kJ} / \mathrm{mol})$ and those reported for stoichiometric reactions on single crystals and supported clusters at lower temperatures $(29-51 \mathrm{~kJ} / \mathrm{mol})$ studies. These differences remain puzzling and may well reflect the contribution of minority and catalytically irrelevant coordinatively unsaturated defects, which do not turn over because of their strong interactions with chemisorbed carbon formed in $\mathrm{C}-\mathrm{H}$ activation steps. It appears, however, that rates and kinetic parameters measured during steady-state catalysis, and reflecting exclusively $\mathrm{CH}_{4}$ activation steps, are most relevant to descriptions of catalytic surfaces at reaction conditions. It is possible that unreactive carbon deposits form at edge or kink steps in small $\mathrm{Ru}$ clusters and $\mathrm{Ru}$ single crystals; these sites would be most effective in stabilizing transition states required for $\mathrm{C}-\mathrm{H}$ bond activation. If so, the resulting carbon species must be entirely unreactive during $\mathrm{CH}_{4}$ reforming reactions, because their surface density (and consequently reaction rates) would otherwise depend on the concentration and identity of co-reactants. They must also form very rapidly during initial contact with $\mathrm{CH}_{4}$ reactants, in view of the lack of detectable deactivation at our reaction conditions.

Differences among activation energies measured on catalysts and on model surfaces were also observed on $\mathrm{Rh},{ }^{25} \mathrm{Pt},{ }^{26} \mathrm{Ir},{ }^{27}$ and $\mathrm{Ni}^{28}$ catalysts. $\mathrm{CO}$ oxidation rates measured on $\mathrm{Rh},{ }^{25} \mathrm{Pt},{ }^{26}$ and $\mathrm{Ir}^{27}$ before and after reforming reactions were identical, indicating that the density and type of exposed metal atoms were unchanged during catalytic reforming reactions. We cannot exclude that a very small fraction of surface atoms, with remarkable reactivity in stoichiometric $\mathrm{CH}_{4}$ activation but unable to turn over, are initially exposed on fresh samples but become unavailable during initial contact with $\mathrm{CH}_{4}$ reactants. We conclude, however, that such sites, if present, do not turn over; 


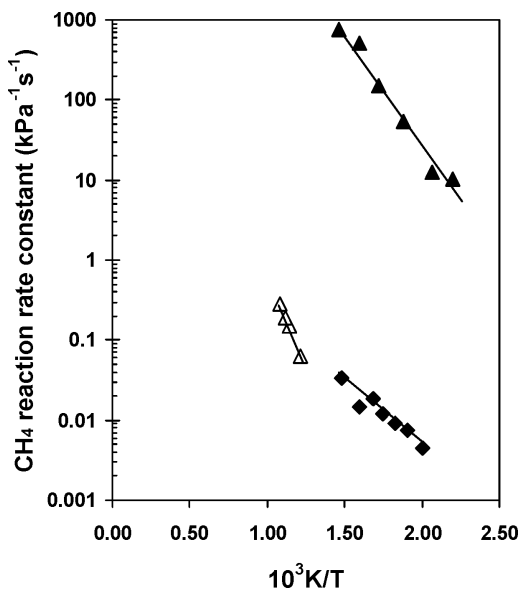

Figure 6. Arrhenius plots for $\mathrm{CH}_{4}$ decomposition rate constants on 3.2 wt $\% \mathrm{Ru} / \mathrm{Al}_{2} \mathrm{O}_{3}$ (this study) $(\triangle), 2.75$ wt $\% \mathrm{Ru} / \mathrm{SiO}_{2}{ }^{38}(\bullet)$, and $\mathrm{Ru}$ $(0001)^{36}(\mathbf{\Lambda})$.

thus, they are not relevant to the analysis and prediction of catalytic rates of $\mathrm{CH}_{4}-\mathrm{H}_{2} \mathrm{O}$ and $\mathrm{CH}_{4}-\mathrm{CO}_{2}$ reactions. Indeed, Wang et al. ${ }^{41}$ examined $\mathrm{CH}_{4}$ decomposition on stepped $\mathrm{Pd}$ (679) surfaces and showed that $\mathrm{C}^{*}$ preferentially forms at steps and kinks, while (111) terraces remain largely uncovered. On Pt surfaces, carbon also forms preferentially at step sites during $n$-hexane reactions, while terrace sites remain uncovered and active for catalytic reactions. ${ }^{42}$ It is not certain that these findings are relevant to Ru surfaces and to the steady-state behavior of catalytic Ru clusters.

Figure 6 shows Arrhenius plots for $\mathrm{CH}_{4}$ decomposition data on 3.2 wt $\% \mathrm{Ru} / \mathrm{Al}_{2} \mathrm{O}_{3}$, from the present study, together with $\mathrm{CH}_{4}$ decomposition rates on $\mathrm{Ru}(0001)^{36}$ and 2.75 wt \% Ru/ $\mathrm{SiO}_{2}{ }^{38}$ at lower temperatures. Measured $\mathrm{CH}_{4}$ decomposition rates on $\mathrm{Ru}(0001)^{36}$ are $\sim 100$ times larger than on $\mathrm{Ru} / \mathrm{Al}_{2} \mathrm{O}_{3}$, while $\mathrm{CH}_{4}$ decomposition rates are similar on $3.2 \mathrm{wt} \% \mathrm{Ru} /$ $\mathrm{Al}_{2} \mathrm{O}_{3}$ and 2.75 wt $\% \mathrm{Ru} / \mathrm{SiO}_{2} .{ }^{38}$ Thus, it appears that the type of defect sites responsible for $\mathrm{CH}_{4}$ activation on large single crystals are not available on small $\mathrm{Ru}$ metal clusters, even though surfaces of small clusters are often described as quite rough and densely populated by coordinatively unsaturated sites. One possibility is that this description becomes inappropriate at high temperatures, because of the tendency of small metal clusters to melt, at least in near-surface regions, well below the melting temperature of the corresponding bulk metal. ${ }^{43,44}$ This process leads to a liquidlike layer a few atoms thick stabilized by a crystalline metal core, which becomes apparent above $800 \mathrm{~K}$ for Pt clusters about $8 \mathrm{~nm}$ in diameter, even though bulk Pt melts at 2042 K. ${ }^{43,44}$ Smaller clusters and the presence of a support to stabilize molten structures would favor these phenomena and lead to significant loss of coordinative unsaturation for the supported Ru clusters of this study (bulk $\mathrm{Ru}$ melts at $2607 \mathrm{~K}$ ). Thus, catalytic reactions at high temperatures, such as $\mathrm{CH}_{4}$ reforming, on small metal clusters may be unable to benefit from coordinative unsaturation, even when such unsaturated sites were able to undergo a catalytic turnover. Although this explanation remains speculative at this point, it deserves additional examination in view of its marked consequences on the choice of models systems that describe faithfully the relevant features of small clusters of catalytic relevance.

Mechanistic Evidence from Kinetic Isotope Effects. Several steady-state isotopic tracer studies and kinetic isotope effect (KIE) measurements were used to probe the role and reversibility of specific elementary steps involved in $\mathrm{CH}_{4}-\mathrm{H}_{2} \mathrm{O}$ and $\mathrm{CH}_{4}-\mathrm{CO}_{2}$, as well as the mechanistic relevance of co-reactants on supported Ru catalysts. Kinetic isotope effects were measured from the relative forward rates of $\mathrm{CH}_{4}-\mathrm{CO}_{2}$ and $\mathrm{CD}_{4}-\mathrm{CO}_{2}$ reactant mixtures at $873 \mathrm{~K}$ on $3.2 \mathrm{wt} \% \mathrm{Ru} / \mathrm{Al}_{2} \mathrm{O}_{3}$ (reduced at $873 \mathrm{~K} ; 44.2 \%$ dispersion). Kinetic isotope effects for $\mathrm{H}_{2} \mathrm{O}$ reforming reactions were obtained from forward reaction rates with $\mathrm{CH}_{4}-\mathrm{H}_{2} \mathrm{O}, \mathrm{CD}_{4}-\mathrm{H}_{2} \mathrm{O}$, or $\mathrm{CD}_{4}-\mathrm{D}_{2} \mathrm{O}$ reactant mixtures also at $873 \mathrm{~K}$.

Normal kinetic isotopic effects were measured for both $\mathrm{CH}_{4}-$ $\mathrm{CO}_{2}$ and $\mathrm{CH}_{4}-\mathrm{H}_{2} \mathrm{O}$ reactions and for $\mathrm{CH}_{4}$ decomposition (Table 2 ), and their values were identical within experimental accuracy (1.40-1.51). These similar values are consistent with equivalent kinetically relevant $\mathrm{C}-\mathrm{H}$ bond activation steps in all three reactions. Forward reaction rates were identical for $\mathrm{CD}_{4}-\mathrm{H}_{2} \mathrm{O}$ and $\mathrm{CD}_{4}-\mathrm{D}_{2} \mathrm{O}$ reactant mixtures, indicating that activation of co-reactants and any reactions between adsorbed species formed from co-reactants and $\mathrm{CH}_{4}$ do not influence overall reaction rates.

Elmasides and Verykios ${ }^{45}$ measured a kinetic isotope value of 1.6 for partial oxidation of $\mathrm{CH}_{4}-\mathrm{O}_{2}$ reactant mixtures at 903 $\mathrm{K}$ on $\mathrm{Ru} / \mathrm{TiO}_{2}$. This value is very similar to those reported here for $\mathrm{H}_{2} \mathrm{O}$ and $\mathrm{CO}_{2}$ reforming reactions, suggesting that partial oxidation, probably occurring via sequential combustion and reforming reactions, may also be limited by $\mathrm{C}-\mathrm{H}$ bond activation. Kinetic isotope effects for $\mathrm{H}_{2} \mathrm{O}$ reforming, $\mathrm{CO}_{2}$ reforming, or $\mathrm{CH}_{4}$ decomposition reactions on $\mathrm{Ru}$ have not been previously reported. The values reported here are similar to those reported previously for $\mathrm{CH}_{4}$ decomposition on $\mathrm{Ni} / \mathrm{SiO}_{2}(1.60)$ at $773 \mathrm{~K}^{46}$ and for $\mathrm{CO}_{2}$ reforming on $\mathrm{Ni} / \mathrm{Al}_{2} \mathrm{O}_{3}(1.45)$ at 873 $\mathrm{K},{ }^{47}$ as well as to those we recently have reported on $\mathrm{Rh}(1.54-$ $1.60),{ }^{25} \mathrm{Pt}(1.58-1.77),{ }^{26} \mathrm{Ir}(1.68-1.75),{ }^{27}$ and $\mathrm{Ni}(1.62-$ 1.71). ${ }^{28}$ Another study, ${ }^{48}$ however, failed to detect a kinetic isotope effect for $\mathrm{CO}_{2}$ reforming on $\mathrm{Ni}$ at near-equilibrium conversions, which led to the proposal that $\mathrm{H}_{2} \mathrm{O}$ or $\mathrm{CO}_{2}$ coreactant activation and chemisorbed oxygen atoms were involved in rate-determining steps. These latter data are inconsistent with the kinetically relevant step and the kinetic isotope effects reported here on Ru-based catalysts; they appear to reflect thermodynamic instead of kinetic isotope effects, because these measurements were made at $\mathrm{CH}_{4}$ conversions near thermodynamic equilibrium.

Bradford and Vannice 2 proposed that $\mathrm{CH}_{4}-\mathrm{CO}_{2}$ reactions proceed on $\mathrm{Ru}$ surfaces via reversible $\mathrm{CH}_{4}$ dissociation to form adsorbed $\mathrm{CH}_{x}$ and $\mathrm{H}$ species, followed by quasi-equilibrated steps, in which $\mathrm{CO}_{2}$ adsorbs, dissociates, reacts with $\mathrm{CH}_{x}$ and hydroxyl groups to form $\mathrm{CH}_{x} \mathrm{O}$ species and $\mathrm{H}$. In this proposal, $\mathrm{CH}_{x} \mathrm{O}$ ultimately dissociates to form adsorbed $\mathrm{CO}$ and $\mathrm{H}$, which then desorb to form $\mathrm{CO}$ and $\mathrm{H}_{2}$. This mechanism provides plausible elementary steps for $\mathrm{CO}_{2}-\mathrm{CH}_{4}$ reactions, but introduces a level of detail that cannot be experimentally tested, because these steps become kinetically irrelevant and the corresponding reactive intermediates are spectroscopically inaccessible when their concentrations are low during steady-state catalysis, as inferred from our kinetic and isotopic studies. We propose instead a set of elementary steps involving simpler intermediates, including chemisorbed carbon, because of its likely formation reactions that lead sequentially from $\mathrm{CH}_{4}$ to $\mathrm{C}^{*}$ with increasing rate as $\mathrm{H}$-atoms are sequentially abstracted from $\mathrm{CH}_{4}{ }^{49}$

These elementary steps are shown as Scheme 1. $\mathrm{CH}_{4}$ decomposes to $\mathrm{C}^{*}$ in a series of elementary $\mathrm{H}$-abstraction steps, with the first abstraction as the kinetically relevant step because of the low prevalent concentration of all $\mathrm{CH}_{x} *$ intermediates. This step is followed by the removal of the fragments formed using $\mathrm{CO}_{2}$ or $\mathrm{H}_{2} \mathrm{O}$ co-reactants. 
SCHEME 1: Sequence of Elementary Steps for $\mathrm{CH}_{4}$ Reforming Reactions on Ru-Based Catalysts

$$
\begin{aligned}
& \mathrm{CH}_{4}+2^{*} \stackrel{\mathrm{k}_{1}}{\longrightarrow} \mathrm{CH}_{3} *+\mathrm{H}^{*} \\
& \mathrm{CH}_{3}{ }^{*}+* \longrightarrow \mathrm{CH}_{2}{ }^{*}+\mathrm{H}^{*} \\
& \mathrm{CH}_{2}{ }^{*}+* \longrightarrow \mathrm{CH}^{*}+\mathrm{H}^{*} \\
& \mathrm{CH}^{*}+* \longrightarrow \mathrm{K}_{2} \mathrm{C}^{*}+\mathrm{H}^{*} \\
& \mathrm{CO}_{2}+2^{*} \stackrel{\mathrm{O}}{\mathrm{CO}} \mathrm{CO}^{*}+\mathrm{O}^{*} \\
& \mathrm{C}^{*}+\mathrm{O}^{*} \underset{k-3}{\stackrel{k_{3}}{\rightleftarrows}} \mathrm{CO}^{*+*} \\
& \mathrm{CO}^{*} \stackrel{K_{4}}{\rightleftarrows} \mathrm{CO}+* \\
& \mathrm{H}^{*}+\mathrm{H}^{*} \circlearrowright \mathrm{H}_{2}{ }^{*+*} \\
& \mathrm{H}_{2} * \stackrel{\mathrm{H}}{\mathrm{H}_{2}{ }^{*}} \\
& \mathrm{H}^{*}+\mathrm{O}^{*} \rightleftarrows \mathrm{OH}^{*+*} \\
& \mathrm{OH}^{*}+\mathrm{H}^{*} \circlearrowright \mathrm{H}_{2} \mathrm{O}^{*+*} \\
& \mathrm{H}_{2} \mathrm{O} * \circlearrowright \mathrm{H}_{2} \mathrm{O}+*
\end{aligned}
$$

In this scheme, $\rightarrow$ denotes an irreversible step, and a quasiequilibrated step, and $k_{i}$ is the rate coefficient and $K_{i}$ the equilibrium constant for step $i$. $\mathrm{CH}_{4}$ irreversibly decomposes in a sequence of elementary steps to form chemisorbed carbon and hydrogen atoms. When $(*)$ is the most abundant surface intermediate, only the rate constant for step (8) appears in the rate expression and the rate becomes proportional to $\mathrm{CH}_{4}$ and independent of the presence or concentration of $\mathrm{CO}_{2}$ or $\mathrm{H}_{2} \mathrm{O}$ co-reactants. Steps (12), and (14)-(19) are assumed to be reversible and quasi-equilibrated. We note that these elementary steps provide pathways for reactions of $\mathrm{CH}_{4}$ with either $\mathrm{CO}_{2}$ or $\mathrm{H}_{2} \mathrm{O}$ and also for water-gas shift reactions, which have been frequently, but inappropriately and nonrigorously, treated as a separate independent kinetic process in many previous studies of $\mathrm{CH}_{4}$ reforming reactions.

Isotopic Tracer and Exchange Evidence for the Reversibility of Specific Elementary Steps. The reversibility of some of the elementary steps shown in Scheme 1 was probed using isotopic tracer and exchange methods. The reversibility of $\mathrm{CH}_{4}$ activation steps was determined from measurements of the rate of formation of $\mathrm{CH}_{x} \mathrm{D}_{4-x}(0<x<4)$ isotopomers during chemical conversion of $\mathrm{CH}_{4} / \mathrm{CD}_{4} / \mathrm{CO}_{2}$ mixtures. $\mathrm{A} \mathrm{CH}_{4} / \mathrm{CD}_{4} /$ $\mathrm{CO}_{2}(1: 1: 2)$ mixture was allowed to react at $873 \mathrm{~K}$ on $3.2 \mathrm{wt}$ $\% \mathrm{Ru} / \mathrm{Al}_{2} \mathrm{O}_{3}$ (treated at $873 \mathrm{~K} ; 44.2 \%$ dispersion). Chemical conversion and isotopic scrambling rates were measured using on-line mass spectrometry after removing $\mathrm{H}_{x} \mathrm{D}_{2-x} \mathrm{O}$ in a trap held at $218 \mathrm{~K}$ (to avoid interference between fragments for $\mathrm{H}_{2} \mathrm{O}$, $\mathrm{HDO}$, and $\mathrm{D}_{2} \mathrm{O}$ and for $\left.\mathrm{CH}_{x} \mathrm{D}_{4-x}\right)$. The rates of $\mathrm{CH}_{x} \mathrm{D}_{4-x}(0<$ $x<4$ ) formation and of methane chemical conversion are shown in Figure 7. The $\mathrm{CH}_{4} / \mathrm{CD}_{4}$ cross-exchange turnover rate, defined as the sum of the rates of formation of $\mathrm{CHD}_{3}, \mathrm{CH}_{2} \mathrm{D}_{2}$ (taken twice), and $\mathrm{CH}_{3} \mathrm{D}$, is $0.18 \mathrm{~s}^{-1}$. The turnover rate for $\mathrm{CH}_{4}$ chemical conversion $\left(3.3 \mathrm{~s}^{-1}\right)$ was about 19 times greater than for isotopic cross-exchange. The approach to equilibrium for this reaction, $\eta$, estimated from the prevalent concentrations of all reactants and products is 0.04 , corresponding to the ratio of the forward overall reaction rate to the reverse reaction rate of 25 , indicating that formation of traces of $\mathrm{CHD}_{3}, \mathrm{CH}_{2} \mathrm{D}_{2}$, and $\mathrm{CH}_{3} \mathrm{D}$ isotopomers is merely due to some slight reversibility

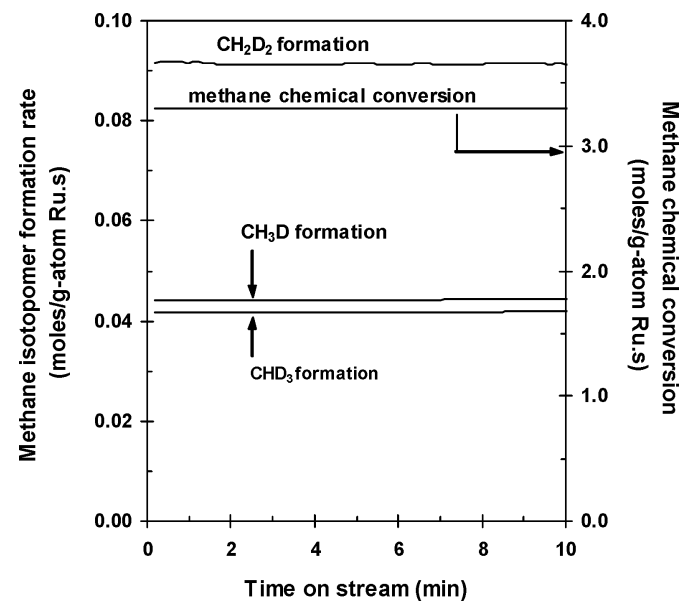

Figure 7. Methane reaction rate and $\mathrm{CH}_{4} / \mathrm{CD}_{4}$ cross-exchange rates during the reaction of $\mathrm{CH}_{4} / \mathrm{CD}_{4} / \mathrm{CO}_{2}$ mixture on $3.2 \mathrm{wt} \% \mathrm{Ru} / \mathrm{Al}_{2} \mathrm{O}_{3}$ catalyst (5 mg of catalyst, $873 \mathrm{~K}, 12.5 \mathrm{kPa} \mathrm{CH}_{4}$ and $\mathrm{CD}_{4}, 25 \mathrm{kPa} \mathrm{CO}_{2}$, balance Ar, total flow rate $80 \mathrm{~cm}^{3} / \mathrm{min}$ ).

for the overall reaction, which rigorously requires that the ratedetermining step become exactly as reversible as the overall reaction. $\mathrm{C}-\mathrm{H}$ bond activation steps on Ru crystallites at 873 $\mathrm{K}$ are irreversible, except as required by the approach of the overall reaction to thermodynamic equilibrium.

The H/D ratio in the dihydrogen formed from equimolar $\mathrm{CH}_{4}-\mathrm{CD}_{4}$ mixtures was greater than one (1.50), and dihydrogen molecules show a binomial isotopomer distribution. This $\mathrm{H} / \mathrm{D}$ ratio reflects the higher reactivity of $\mathrm{CH}_{4}$ relative to $\mathrm{CD}_{4}$, as shown from independent reaction rates for these two methane isotopomers (1.42). The binomial distribution of dihydrogen isotopomers indicates that recombinative hydrogen desorption steps are quasi-equilibrated during $\mathrm{CH}_{4}-\mathrm{CO}_{2}$ reactions on $\mathrm{Ru}$ at $873 \mathrm{~K}$.

Reactions of $\mathrm{CH}_{4} / \mathrm{CO}_{2} / \mathrm{D}_{2}(1: 1: 0.2)$ mixtures at $873 \mathrm{~K}$ on 3.2 wt $\% \mathrm{Ru} / \mathrm{Al}_{2} \mathrm{O}_{3}$ were used to probe the reversibility of elementary steps leading to the formation of water and dihydrogen. Here, water was not removed before mass spectrometric analysis, and all transfer lines were kept above $373 \mathrm{~K}$ to prevent water condensation. No deuterated methane isotopomers were detected, as expected from the irreversible nature of $\mathrm{C}-\mathrm{H}$ bond activation steps; as a result, water isotopomer measurements were unaffected by mass fragments from deuterated methane molecules. The $\mathrm{H} / \mathrm{D}$ fraction expected if all $\mathrm{H}$-atoms in the converted $\mathrm{CH}_{4}$ molecules and all D-atoms in the inlet $\mathrm{D}_{2}$ stream contributed to surface intermediates is 0.76 . The water molecules formed during reaction and the dihydrogen molecules in the effluent stream both contained identical H/D ratios of 0.74 . Thus, dihydrogen and water molecules and their corresponding precursors in the chemisorbed phase are in quasi-equilibrium. Table 3 shows the isotopomer distribution in water molecules formed from $\mathrm{CH}_{4} / \mathrm{CO}_{2} / \mathrm{D}_{2}$ reactant mixtures. The isotopomer distribution is binomial with a D-content identical to that in the available reactant pool; this is consistent with fast and quasiequilibrated recombination of $\mathrm{H}^{*}$ and $\mathrm{OH}^{*}$ in step (18) in Scheme 1. Binomial distributions were also observed for dihydrogen isotopomers, as expected from reversible and quasiequilibrated recombinative hydrogen desorption steps (step (15) and (16) in Scheme 1) during $\mathrm{CH}_{4} / \mathrm{CO}_{2}$ reactions on Ru-based catalysts. In view of the kinetic equivalence of elementary steps involved in $\mathrm{CH}_{4}$ reactions with $\mathrm{CO}_{2}$ and $\mathrm{H}_{2} \mathrm{O}$, we consider these conclusions to be also valid for $\mathrm{CH}_{4}-\mathrm{H}_{2} \mathrm{O}$ reactions on $\mathrm{Ru}$ based catalysts.

The reversibility of $\mathrm{CO}_{2}$ activation steps (step (12) in Scheme 1) was probed using ${ }^{12} \mathrm{CH}_{4} /{ }^{12} \mathrm{CO}_{2} /{ }^{13} \mathrm{CO}$ (1:1:0.4) reactant 
TABLE 3: Distribution of Water Isotopomers during Reactions of $\mathrm{CH}_{4} / \mathrm{CO}_{2} / \mathrm{D}_{2}$ Mixtures on $3.2 \mathrm{wt} \% \mathrm{Ru} / \mathrm{Al}_{2} \mathrm{O}_{3}$ Reduced at $873 \mathrm{~K}\left(873 \mathrm{~K}, 16.7 \mathrm{kPa} \mathrm{CH}_{4}, 16.7 \mathrm{kPa} \mathrm{CO} 2,3.3\right.$ $\mathrm{kPa} \mathrm{D}_{2}$, balance Ar, total flow rate $150 \mathrm{~cm}^{3} / \mathrm{min}$ )

\begin{tabular}{ccc}
\hline & \multicolumn{2}{c}{ Distribution $(\%)$} \\
\cline { 2 - 3 } isotopomer & $\begin{array}{c}\text { measured } \\
(\mathrm{H} / \mathrm{D}=0.74)\end{array}$ & $\begin{array}{c}\text { binomial } \\
\left(\mathrm{H}^{a} \mathrm{D}^{a}=0.76\right)\end{array}$ \\
\hline $\mathrm{H}_{2} \mathrm{O}$ & 0.19 & 0.19 \\
$\mathrm{HDO}$ & 0.48 & 0.49 \\
$\mathrm{D}_{2} \mathrm{O}$ & 0.33 & 0.32
\end{tabular}

a $(\mathrm{H} / \mathrm{D})$ ratio predicted from $\mathrm{H}$ in reacted methane and $\mathrm{D}_{2}$ in ambient stream if complete mixing between the two isotopes occurred during reaction.

mixtures at $873 \mathrm{~K}$ on $3.2 \mathrm{wt} \% \mathrm{Ru} / \mathrm{Al}_{2} \mathrm{O}_{3}$. The ${ }^{13} \mathrm{C}$ fraction in $\mathrm{CO}(0.275)$ and $\mathrm{CO}_{2}(0.256)$ molecules in the effluent are similar to each other at all reaction temperatures, even though the inlet reactant mixture contained isotopically pure ${ }^{12} \mathrm{CO}_{2}$ and ${ }^{13} \mathrm{CO}$. The ${ }^{13} \mathrm{C}$ content corresponds to complete chemical and isotopic equilibration between $\mathrm{CO}$ and $\mathrm{CO}_{2}$, even at $\mathrm{CH}_{4}$ chemical conversion levels $(6.4 \%)$ far from equilibrium $(\eta=0.06)$. These data indicate that $\mathrm{CO}_{2}$ activation steps are much faster than kinetically relevant $\mathrm{CH}_{4}$ dissociation steps, and that steps (12) and (14) occur in both directions many times in the time required for a $\mathrm{CH}_{4}$ chemical conversion turnover. Thus, $\mathrm{CO}_{2}$ activation steps are reversible and quasi-equilibrated during $\mathrm{CH}_{4}-\mathrm{CO}_{2}$ reactions and by kinetic analogy also during $\mathrm{CH}_{4}-\mathrm{H}_{2} \mathrm{O}$ reactions at similar reaction conditions. Only trace amounts of ${ }^{13} \mathrm{CH}_{4}$ were detected during reactions of ${ }^{12} \mathrm{CH}_{4} /{ }^{12} \mathrm{CO}_{2} /{ }^{13} \mathrm{CO}$ mixtures, as expected from the low value of $\eta(0.06)$ during these experiments, which lead to essentially irreversible conversion of $\mathrm{CH}_{4}$ to $\mathrm{H}_{2}$ and $\mathrm{CO}$.

Steps (12) and (14)-(19) in Scheme 1 describe the reverse water-gas shift reaction, which must, in view of the equilibrated nature of its component steps, also be quasi-equilibrated during $\mathrm{CH}_{4}$ reforming reactions on $\mathrm{Ru}$-based catalyst (Figure 2). Indeed, we find that the approach to equilibrium for this reaction, estimated from the prevalent concentrations of all reactants and products, is near unity at all conditions (Figure 2).

These isotopic studies were carried out on a $3.2 \mathrm{wt} \% \mathrm{Ru} /$ $\mathrm{Al}_{2} \mathrm{O}_{3}$ and predominately at $873 \mathrm{~K}$, but the similar rate expressions obtained at all temperatures and on all catalysts do not indicate any mechanistic shifts with changes in reaction temperature or catalyst composition and thus support the general relevance of the proposed elementary steps. We note that these elementary steps also provide a rigorous basis for kinetic treatments of carbon filament formation during $\mathrm{CH}_{4}$ reforming reactions by defining a concentration or thermodynamic activity for chemisorbed carbon as a function of prevalent pressures and of rate constants and equilibrium constants for elementary steps, as we discuss in detail elsewhere. ${ }^{25-28}$

Dispersion and Support Effects on $\mathrm{H}_{2} \mathrm{O}$ and $\mathrm{CO}_{2}$ Reforming on $\mathrm{Ru}$. Ru clusters with a range of dispersion were prepared by varying the metal content, the reduction temperature, and the identity of the support. Turnover rates were calculated from forward rates normalized by the number of exposed $\mathrm{Ru}$ atoms; they are shown for $\mathrm{CH}_{4}-\mathrm{CO}_{2}, \mathrm{CH}_{4}-\mathrm{H}_{2} \mathrm{O}$, and $\mathrm{CH}_{4}$ decomposition reactions in Table $1 . \mathrm{CH}_{4}-\mathrm{CO}_{2}$ turnover rates reported by Bradford and Vannice, ${ }^{2}$ Ferreria-Aparicio et al., ${ }^{12}$ Portugal et al., ${ }^{18}$ and Solymosi et al. ${ }^{3}$ on Ru-based catalysts are also shown in Table 1. We have corrected these literature rates for approach to equilibrium and extrapolated to our reaction conditions (873 $\mathrm{K}, 20 \mathrm{kPa} \mathrm{CH}$ ) using a first-order $\mathrm{CH}_{4}$ dependence and the activation energies reported in each literature report $(92.5 \mathrm{~kJ} /$ mol, Solymosi et al. ${ }^{3} ; 106 \mathrm{~kJ} / \mathrm{mol}$, Bradford et al. ${ }^{2}$ ). Portugal et

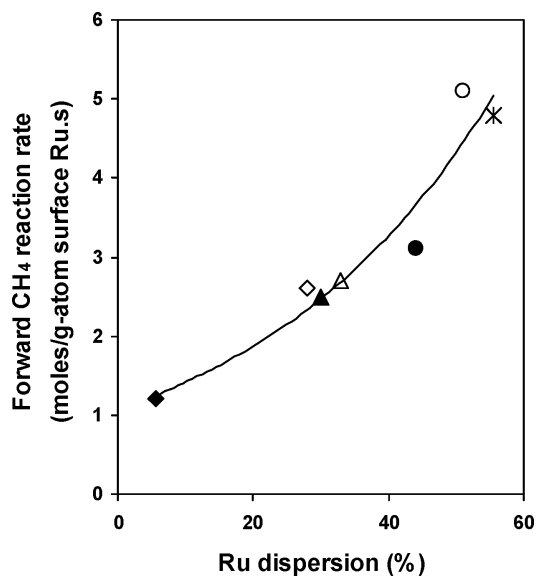

Figure 8. Forward $\mathrm{CH}_{4}$ reaction rate for $\mathrm{CO}_{2}$ reforming of $\mathrm{CH}_{4}$ vs metal dispersion on different Ru-based catalysts $\left(873 \mathrm{~K}, 20 \mathrm{kPa} \mathrm{CH}_{4}\right.$, $(\diamond) 1.0$ wt $\% \mathrm{Ru} / \gamma-\mathrm{Al}_{2} \mathrm{O}_{3}$ (ref 3), (C) $1.0 \mathrm{wt} \% \mathrm{Ru} / \mathrm{NaY}$ (ref 18), ( $\left.\triangle\right) 3.2$ wt $\% \mathrm{Ru} / \mathrm{ZrO}_{2}$ (this study), (๑) $3.2 \mathrm{wt} \% \mathrm{Ru} / \gamma-\mathrm{Al}_{2} \mathrm{O}_{3}$ reduced at 1023 $\mathrm{K}$ (this study), (O) $1.6,3.2 \mathrm{wt} \% \mathrm{Ru} / \gamma-\mathrm{Al}_{2} \mathrm{O}_{3}$ reduced at $873 \mathrm{~K},\left(^{*}\right)$ 0.64 wt $\% \mathrm{Ru} / \gamma-\mathrm{Al}_{2} \mathrm{O}_{3}(\operatorname{ref}(12))$.

al. ${ }^{18}$ and Ferreria-Aparicio et al. ${ }^{12}$ did not report activation energies; therefore, we have used our value of the activation energy $(96 \mathrm{~kJ} / \mathrm{mol})$ in extrapolating their data to our reaction conditions. Forward $\mathrm{CH}_{4}$ reaction rates were reported by Bradford et al. ${ }^{2}$ and Portugal et al., ${ }^{18}$ but the net rates reported by Solymosi et al. ${ }^{3}$ and Ferreria-Aparicio et al. ${ }^{12}$ were converted to forward rates, using $\eta$ values of 0.05 and 0.1 , respectively, based on their respective $\mathrm{CH}_{4}$ conversion levels.

Identical dispersion effects and turnover rate values were obtained for $\mathrm{CH}_{4}-\mathrm{H}_{2} \mathrm{O}, \mathrm{CH}_{4}-\mathrm{CO}_{2}$, and $\mathrm{CH}_{4}$ decomposition reaction rates (Table 1), as expected from their rigorous mechanistic equivalence. Turnover rates increased monotonically with increasing $\mathrm{Ru}$ dispersion for both reactions, suggesting that coordinatively unsaturated $\mathrm{Ru}$ surface atoms, likely to be prevalent in small crystallites even if they become mobile at high temperatures, are more active than those in lowindex planes predominately exposed on large $\mathrm{Ru}$ crystallites. Edge and corner atoms, with fewer Ru neighbors than those on terraces, bind $\mathrm{CH}_{x}$ and $\mathrm{H}$ more strongly and apparently decrease the energy required to form the relevant transition state for $\mathrm{C}-\mathrm{H}$ bond activation. ${ }^{36}$ No previous literature reported systematic $\mathrm{Ru}$ dispersion effects on $\mathrm{CH}_{4}$ reaction rates, but similar effects of coordinative unsaturation were previously reported on other metal surfaces. ${ }^{24-28,50,51}$. Klier et al. ${ }^{24}$ found that $\mathrm{CH}_{4}$ dissociation rates on a Pd single crystal increased with increasing density of steps and kinks. These coordinative unsaturated surface atoms showed reaction rates 10-100 times larger than on hexagonal closed-packed $\operatorname{Pd}(111)$ surfaces. Johnson and Weinberg ${ }^{50}$ reported that defects sites on Ir surfaces were much more active than terrace sites for alkane dissociation reactions. Molecular beam studies by Weaver et al. ${ }^{51}$ showed that surface defects in $\operatorname{Pt}(111)$ markedly increased alkane dissociation rates.

The identity of the support did not directly influence turnover rates (Table 1, Figure 8), but it can influence $\mathrm{Ru}$ dispersion and, in this manner, also turnover rates. Matsui et al. ${ }^{9}$ have reported much higher $\mathrm{CH}_{4}$ conversions on $\mathrm{Ru} / \mathrm{Y}_{2} \mathrm{O}_{3}$ and $\mathrm{Ru} /$ $\mathrm{ZrO}_{2}(25-29 \%)$ than on $\mathrm{Ru} / \mathrm{SiO}_{2}(12 \%)$ and attributed these effects to $\mathrm{CO}_{2}$ activation on the supports, but neither $\mathrm{Ru}$ dispersions nor turnover rates were reported. These support effects are inconsistent with our findings on $\mathrm{Al}_{2} \mathrm{O}_{3}$ and $\mathrm{ZrO}_{2}$ supports and with the kinetic irrelevance of co-reactant activation during $\mathrm{CH}_{4}$ reforming reactions on $\mathrm{Ru}$-based catalysts. 
Figure 8 shows that literature turnover rates show a consistent effect of dispersion, irrespective of the identity of the support, except for the data Bradford et al. ${ }^{2}$ on $\mathrm{Ru} / \eta-\mathrm{Al}_{2} \mathrm{O}_{3}$, which showed higher turnover rates and $\mathrm{Ru} / \mathrm{C}$, which showed lower turnover rate. Once $\mathrm{Ru}$ dispersions are used to normalize reaction rates, turnover rates increased monotonically with increasing $\mathrm{Ru}$ dispersion. These dispersion effects, and the measured turnover rates, are identical for $\mathrm{CH}_{4}$ reactions with either $\mathrm{H}_{2} \mathrm{O}$ or $\mathrm{CO}_{2}$ co-reactants and also for $\mathrm{CH}_{4}$ decomposition on supported $\mathrm{Ru}$ catalysts (Table 1 ).

\section{Conclusions}

Isotopic studies and forward reaction rate measurements led to a simple mechanistic picture and to a unifying kinetic treatment of $\mathrm{CH}_{4}-\mathrm{CO}_{2}, \mathrm{CH}_{4}-\mathrm{H}_{2} \mathrm{O}$, and $\mathrm{CH}_{4}$ decomposition reactions and of water-gas shift on Ru-based catalysts. $\mathrm{CH}_{4}$ reactions are limited by $\mathrm{C}-\mathrm{H}$ bond activation and unaffected by the identity or concentration of co-reactants or of the presence of reaction products. Turnover rates were identical for $\mathrm{CH}_{4}$ decomposition, $\mathrm{CO}_{2}$ reforming, and $\mathrm{H}_{2} \mathrm{O}$ reforming reactions, and activation energies were similar for the latter two reactions. The kinetic relevance of $\mathrm{C}-\mathrm{H}$ bond activation was confirmed by kinetic isotope effect measurements; isotope effects were identical for $\mathrm{CH}_{4}-\mathrm{CO}_{2}$ and $\mathrm{CH}_{4}-\mathrm{H}_{2} \mathrm{O}$ reactions and for $\mathrm{CH}_{4}$ decomposition. Cross-exchange rates are much smaller than chemical conversion rates for $\mathrm{CH}_{4} / \mathrm{CD}_{4} / \mathrm{CO}_{2}$ mixtures and indicate that $\mathrm{C}-\mathrm{H}$ bond activation is exactly as reversible as the overall chemical reaction. Reactions of the $\mathrm{CH}_{4} / \mathrm{CO}_{2} / \mathrm{D}_{2}$ mixture led to binomial isotopomer distributions of water and dihydrogen and to D-contents identical to those expected from quasi-equilibrated water and dihydrogen desorption steps. ${ }^{12} \mathrm{CH}_{4} /{ }^{12} \mathrm{CO}_{2} /{ }^{13} \mathrm{CO}$ mixtures led to identical ${ }^{13} \mathrm{C}$ contents in $\mathrm{CO}$ and $\mathrm{CO}_{2}$, consistent with equilibrated $\mathrm{CO}_{2}$ dissociation steps. These results demand that the water-gas shift reaction be at thermodynamic equilibrium during $\mathrm{CO}_{2}$ and $\mathrm{H}_{2} \mathrm{O}$ reforming reactions on $\mathrm{Ru}$-based catalysts, as indeed found from the chemical composition of the reactor effluent at all reaction conditions.

Forward turnover rates for both $\mathrm{CO}_{2}$ and $\mathrm{H}_{2} \mathrm{O}$ reforming increased monotonically with increasing $\mathrm{Ru}$ dispersion, suggesting that the coordinatively unsaturated surface atoms prevalent in small crystallites are significantly more active than those in the low-index planes predominately exposed on large crystallites. No effects of supports, beyond their influence on $\mathrm{Ru}$ dispersion, were detected, as expected from the kinetic irrelevance of co-reactant activation steps, which have been previously and nonrigorously claimed to occur on support sites.

Acknowledgment. This study was supported by BP as part of the Methane Conversion Cooperative Research Program at the University of California at Berkeley. Helpful technical discussions with Drs. John Collins and Theo Fleisch (BP) are gratefully acknowledged.

\section{Appendix}

The effects of the catalyst pellet size and the extent of dilution within the catalyst particles were studied on $3.2 \mathrm{wt} \% \mathrm{Ru} / \mathrm{Al}_{2} \mathrm{O}_{3}$ (reduced at $873 \mathrm{~K}$, Ru dispersion $44.2 \%$ ) for $\mathrm{H}_{2} \mathrm{O} / \mathrm{CH}_{4}$ reactions at $873 \mathrm{~K}$. The results are shown in Figure 9. Varying the diameter of catalyst pellets $(250-425$ vs $63-106 \mu \mathrm{m})$ or the extent of dilution within the pellets (5:1 to 10:1) did not influence net $\mathrm{CH}_{4}$ reaction rates, indicating that measured net rates are not affected in any way by intrapellet or interpellet

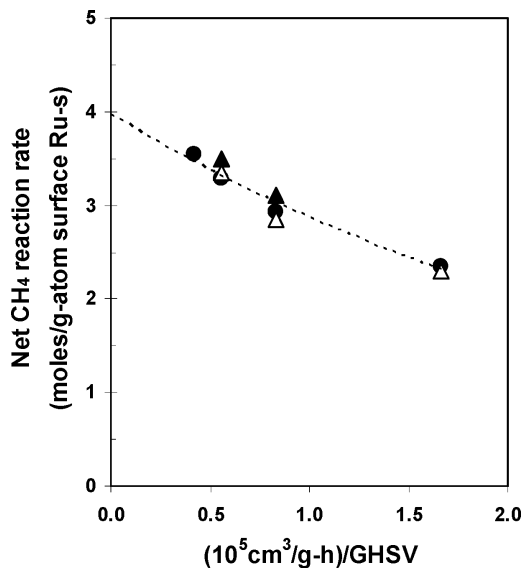

Figure 9. Net $\mathrm{CH}_{4}$ turnover rates versus residence time for $\mathrm{CH}_{4}-$ $\mathrm{H}_{2} \mathrm{O}$ reaction on $3.2 \mathrm{wt} \% \mathrm{Ru} / \mathrm{Al}_{2} \mathrm{O}_{3}$ at $873 \mathrm{~K}((\bullet) 10 \mathrm{mg}$ of catalyst diluted with $100 \mathrm{mg}$ of $\mathrm{Al}_{2} \mathrm{O}_{3}$ within pellets, then diluted with $500 \mathrm{mg}$ of ground quartz, pellet size $250-425 \mu \mathrm{m} ;(\Delta) 10 \mathrm{mg}$ of catalyst diluted with $50 \mathrm{mg}$ of $\mathrm{Al}_{2} \mathrm{O}_{3}$ within pellets, then diluted with $500 \mathrm{mg}$ of ground quartz, pellet size $250-425 \mu \mathrm{m}$; (A) $10 \mathrm{mg}$ of catalyst diluted with 50 $\mathrm{mg}$ of $\mathrm{Al}_{2} \mathrm{O}_{3}$ within pellets, then diluted with $500 \mathrm{mg}$ of ground quartz, pellet size $63-106 \mu \mathrm{m})$.

transport artifacts. Extrapolating the net reaction rate to zero residence time gives forward $\mathrm{CH}_{4}$ reaction rates.

\section{References and Notes}

(1) Fischer, V. F.; Tropsch, H. Brennstoff-Chemie 1928, 3, 39.

(2) Bradford, M. C. J.; Vannice, M. A. J. Catal. 1999, 183, 69.

(3) Solymosi, F.; Kustan, G.; Erohelyi, A. Catal. Lett. 1991, 11, 149.

(4) Claridge, J. B.; Green, M. L. H.; Tsing S. C. Catal. Today 1994, 12,455 .

(5) Vernon, P. D. F.; Green, M. L. H.; Cheetham, A. K.; Ashcroft, A. T. Catal. Today 1992, 13, 417.

(6) Ashcroft, A. T.; Cheetham, A. K.; Green, M. L. H.; Vernon, P. D. F. Nature 1991, 352, 225.

(7) Basini, L.; Sanfilippo, D. J. Catal. 1995, 157, 162.

(8) Matsui, N.; Nakagawa, K.; Ikenaga, N.; Suzuki, T. J. Catal. 2000, 194, 115.

(9) Matsui, N.; Anzai, K.; Akamatsu, N.; Nakagawa, K.; Ikenaga, N.; Suzuki, T. Appl. Catal. A: General 1999, 179, 247.

(10) Mark, F. M.; Maier, W. F. J. Catal. 1996, 164, 122.

(11) Ferreira-Aparicio, P.; Rodriguez-Ramos, I.; Anderson, J. A.; Guerrero-Ruiz, A. Appl. Catal. A 2000, 202, 183.

(12) Ferreira-Aparicio, P.; Marquez-Alvarez, C.; Rodriguez-Ramos, I.; Schuurman, Y.; Guerrero-Ruiz, A.; Mirodatos, C. J. Catal. 1999, 184, 202

(13) Sutton, D.; Parle, S. M.; Ross, J. R. H. Fuel Process. Technol. 2002, 75,45 .

(14) Bradford, M. C. J.; Vannice, M. A. Catal. Today 1999, 50, 87

(15) Qin, D.; Lapszewicz, J. Catal. Today 1994, 21, 551.

(16) Rostrup-Nielsen, J. R.; Hansen, J. H. B. J. Catal. 1993, 144, 38.

(17) Guerrero-Ruiz, A.; Ferreira-Aparicio, P.; Bachiller-Baeza, M. B.; Rodriguez-Ramos, I. Catal. Today 1998, 46, 99.

(18) Portugal, U. L.; Marques, C. M. P.; Araujo, E. C. C.; Morales, E. V.; Giotto, M. V.; Bueno, J. M. C. Appl. Catal. A 2000, 193, 173.

(19) Schuurman, Y.; Mirodatos, C.; Ferreira-Aparicio, P.; RodriguezRamos, I.; Guerrero-Ruiz, A. Catal. Lett. 2000, 66, 33.

(20) Pitchai, R.; Klier, K. Catal. Rev.-Sci. Eng. 1986, 28, 13.

(21) Boudart, M. Adv. Catal. 1969, 20, 153.

(22) McMaster, M. C.; Madix, R. J. J. Chem. Phys. 1993, 98, 15.

(23) Gee, A. T.; Hayden, B. E.; Mormiche, C.; Kleyn, A. W.; Riedmuller, B. J. Chem. Phys. 2003, 118, 3334.

(24) Klier, K.; Hess, J. S.; Herman, R. G. J. Chem. Phys. 1997, 107, 4033.

(25) Wei, J.; Iglesia, E. J. Catal., in press.

(26) Wei, J.; Iglesia, E., J. Phys. Chem. B 2004, 108, 4094.

(27) Wei, J.; Iglesia, E. Angew Chem. Int. Ed., in press.

(28) Wei, J.; Iglesia, E., J. Catal., in press.

(29) Bahlawane, N.; Watanabe, T. J. Am. Ceram. Soc. 2000, 83, 2324.

(30) Barton, D. G. Ph.D. dissertation, University of California at Berkeley, 1998

(31) Mazzieri, V.; Coloma-Pascual, F.; Arcoya, A.; Largentière, P. C.; Fígoli, N. S. Appl. Surf. Sci. 2003, 210, 222.

(32) Price, G. L.; Iglesia, E. Ind. Eng. Chem. 1989, 28, 839. 
(33) Stull, D. R.; Edgar, F.; Westrum, J.; Sinke, G. C. The Thermodynamics of Organic Compounds; Robert, E., Ed.; Krieger Publishing Co. Malabar, FL, 1987.

(34) Boudart, M.; Djega-Mariadassou, G. The Kinetics of Heterogeneous Catalytic Reactions; Princeton University Press: Princeton, NJ, 1984.

(35) Dumesic, J. A.; Rudd, D. F.; Rekoske, J. E.; Trevino, A. A. The Microkinetics of Heterogeneous Catalysis; American Chemical Society: Washington, DC, 1993.

(36) Egeberg, R. C.; Ullmann, S.; Alstrup, I.; Mullins, C. B.; Chorkendorff, I. Surf. Sci. 2002, 497, 183.

(37) Wu, M. C.; Goodman, D. W. Surf. Sci. 1994, 306, L529.

(38) Carstens, J. N.; Bell, A. T. J. Catal. 1996, 161, 423.

(39) Ciobica, I. M.; Frechard, F.; van Santen, R. A.; Kleyn, A. W.; Hafner, J. J. Phys. Chem. B 2000, 104, 3364.

(40) Liu, J. P.; Hu, P. J. Am. Chem. Soc. 2003, 125, 1958.

(41) Wang, Y.; Herman, R. G.; Klier, K. Surf. Sci. 1992, 279, 33.
(42) Davis, S. M.; Zaera, F.; Somorjai, G. A. J. Catal. 1982, 77, 439.

(43) Wang, Z. L.; Ahmad, T. S.; El-Sayed, M. A. Surf. Sci. 1997, 380, 302 .

(44) Wang, Z. L.; Petroski, J. M.; Green, T. C.; El-Sayed, M. A. J. Phys. Chem. B 1998, 102, 6145.

(45) Elmasides, C.; Verykios, X. E. J. Catal. 2001, 203, 477.

(46) Otsuka, K.; Kobayashi, S.; Takenaka, S. J. Catal. 2001, $200,4$.

(47) Osaki, T.; Horiuchi, T.; Suzuki, K.; Mori, T. Catal. Lett. 1997, 44, 19.

(48) Schuurman, Y.; Kroll, V. C. H.; Ferreira-Aparicio, P.; Mirodatos, C. Catal. Today 1997, 38, 129.

(49) Au, C.; Ng, C.; Liao, M. J. Catal. 1999, 185, 12.

(50) Johnson, D. F.; Weinberg, W. H. J. Chem. Phys. 1994, 101, 6289.

(51) Weaver, J. F.; Krzyzowski, M. A.; Madix, R. J. Surf. Sci. 1997, 391, 150. 